\title{
How Does Illiquidity Affect Delegated Portfolio Choice?*
}

\author{
Luis Goncalves-Pinto \\ Marshall School of Business \\ University of Southern California
}

October 30, 2009

* I thank Michael Gallmeyer (discussant), Pedro Matos, Salvatore Miglietta, Antonios Sangvinatsos, Breno Schmidt, Joshua Shemesh, Costas Xiouros, Fernando Zapatero, participants at the EFA 2009 Meetings in Bergen and at the LBS 9th Trans-Atlantic Doctoral Conference, and seminar participants at USC Marshall School of Business, for helpful comments and suggestions. I am responsible for all remaining errors. I would like to thank Calouste Gulbenkian Foundation for financial support. Address for correspondence: Finance and Business Economics Department, Marshall School of Business, University of Southern California, 3670 Trousdale Parkway, Bridge Hall 308, Los Angeles, CA 90089-0804, USA. Tel: (213) 210-3992. E-mail: lgoncalv@usc.edu 


\title{
How Does Illiquidity Affect Delegated Portfolio Choice?
}

\begin{abstract}
In a continuous-time dynamic portfolio choice framework, I study the problem of an investor who exogenously decides to delegate the administration of her savings to a risk-averse money manager who trades multiple risky assets in a thin market. I consider a manager who is rewarded for increasing the value of assets under management, which is the product of both the manager's portfolio allocation decisions, taken over the investment period, and the money flows into and out of the fund, as a result of the portfolio performance relative to an exogenous benchmark. The model proposed here shows that, whenever the manager can substitute between more illiquid and less illiquid risky assets, she is likely to choose to hold an initial portfolio that is skewed toward more illiquid assets, and to gradually shift toward less illiquid assets over the investment period. The model further shows that several misalignments of objectives between the investor and the manager can lead to large utility costs on the part of the investor, and that these costs decrease with asset illiquidity. Solving for the shadow costs of illiquidity, the model indicates that delegated rather than direct investing is likely to lead to larger price discounts.
\end{abstract}

Keywords: Illiquidity, Portfolio Delegation, Benchmarking

JEL Classification: G11, G12, D60, D81. 


\section{Introduction}

In this paper, I investigate how the inability to buy and sell assets as desired, affects the problem of an investor who decides not to invest her savings directly, but instead decides to hire a money manager to do so on a discretionary basis.

As was recognized by Allen (2001), asset pricing theory cannot be indifferent to the fact that portfolio delegation or institutional ownership have become increasingly dominant features of developed financial markets. Indeed, even though direct accessibility to financial markets has been improving over the years, the tendency for individual investors to delegate the administration of their savings to professional money managers has not slowed down. According to data from the Federal Reserve Board, back in 1952, individual investors directly held over $90 \%$ of corporate equities, while by the end of 2008 this proportion was down to less than $25 \%$. At the same time, the fraction of equities held by investment funds (including mutual funds, closed-end funds, and exchange-traded funds) rose from $2.9 \%$ to $28.5 \%$. By hiring money managers to administer theirs savings, investors lose control over the composition of funds' portfolios and become subject to numerous misalignments of objectives that can be very costly. For instance, according to a survey by the Investment Company Institute (the national association of U.S. investment companies), by the end of 2007 over $90 \%$ of U.S. mutual fund-owning households indicated "saving-for-retirement" as their primary financial goal. However, fund managers, who are concerned with their reputations and careers, and who may derive private benefits from being in charge of large funds, have incentives to boost short-term performance to increase the value of their funds' assets, actions that may be inconsistent with investors' risk tolerance and long-run investment goals. ${ }^{1}$ It is therefore important to understand what factors affect delegated portfolio choice, and how they do so.

To the best of my knowledge, existing models of delegated portfolio choice have assumed that investors and fund managers can trade assets continuously and with no 
frictions. Increasingly, however, both academics and practitioners recognize that, in addition to risk and return, liquidity (or the lack of it) is a critical component of the investment equation. In reality, when liquidity dries up, investors and money managers lose control over their portfolio allocations and may be forced to sit on their hands for long periods of time, unable to trade out of mistakes they may have made with less liquid assets. What's more, investing in illiquid assets presents an interesting set of challenges and risks. In particular, their true value is often unknown, their historical performance can often be misleading, and they typically cost more to transact. In addition, as if low liquidity wasn't already difficult enough to deal with, volatility also typically increases in down and more illiquid markets. In the face of such uncertainty, investors and money managers' optimal portfolio policies necessarily diverge from those they would choose in a less constrained context. Recall that the performance of mutual fund managers is usually measured relative to the performance of a benchmark, like the Wilshire 5000 or the S\&P 500, which are usually simply paper-based calculations of stock prices as they are quoted on the exchange. However, as fund managers attempt to make a transaction, prices of illiquid assets can differ significantly from those quoted on the exchange. The flows into and out of the managers' funds depend on the performance of their portfolios relative to these benchmarks, and the presence of illiquidity makes it more difficult for managers to track benchmarks and grow the value of their funds' assets. Given that illiquidity can result in a failure to transact, money managers' performance, not to mention their jobs, can be put at stake, and so the presence of illiquidity can ultimately affect managers' preferences and incentives.

In this paper, I relax the assumption of continuous and frictionless asset trading that has underlied existing models of delegated portfolio management to date and, using a familiar partial-equilibrium dynamic portfolio choice framework, I study the problem of an individual investor who exogenously delegates the administration of her savings to a fund manager who trades multiple risky assets in a market where prices are abnormally volatile and assets have limited marketability. I consider that the exogenous 
portfolio delegation decision is grounded on the assumption that, in comparison with the individual investor, the money manager is subject to lower transaction costs, lower opportunity costs for engaging in active portfolio management, better information or ability, or better investing education. In addition, I consider a risk-averse manager whose compensation scheme is set exogenously and which is proportional to the value of her fund's assets under management at some terminal date. This fund's terminal value is the product of both the manager's portfolio allocation decisions, taken over the investment period, and the money flows into and out of the fund which are allowed to happen only once on the investment horizon and which depend on the manager's portfolio performance relative to a reference benchmark.

I model illiquidity according to Longstaff (2001), in which market participants are constrained to trading strategies that are of bounded variation, and investigate the extent to which the restricted ability to initiate or unwind portfolio positions affects the fund manager's optimal asset allocations and risk-shifting incentives created by benchmarking, and how that affects the welfare costs generated to a delegating investor whose objectives may diverge from those of the fund manager. I study this problem in a Black-Scholes-Merton economy in which market participants have access to one riskless asset and two risky assets whose returns can be correlated. I consider liquidity restrictions to be asset-specific. Both of the risky assets can be traded at the beginning of the investment period, but one of them cannot be traded again until after a "blackout" period, while the other is allowed to be traded, even if just in limited amounts, over the investment period. Market participants therefore have limited ability to rebalance their portfolio positions at any price, a characteristic that resembles the concept of depth in financial markets. Examples of risky assets subject to these sorts of trading restrictions are stock of firms that are not publicly traded, restricted and unregistered stock in publicly traded companies, or a large holding of a particular stock that the market cannot absorb.

My analysis shows that, compared to when there are no liquidity constraints, when- 
ever a fund manager can choose between two risky assets that are identical in all respects except in terms of liquidity, she is likely to hedge her portfolio by lowering her total initial risk exposure, moving capital away from riskier investments and towards the safest one. This analysis confirms that in the framework of Longstaff (2001) market illiquidity endogenously generates funding illiquidity. ${ }^{2}$ In other words, because the fund manager's value of assets under management is a process bounded below by zero, and given that under liquidity constraints, returns of each risky asset cannot be replicated by those of the remaining assets in the portfolio, endogenously the manager cannot borrow to invest more in risky assets, because the prices of the illiquid risky assets can quickly fall, making it impossible to sell enough of those assets to guarantee positive terminal wealth. In addition, due to diversification reasons, and to incentives for the hedging of portfolio weight uncertainty, initial portfolio allocations on the two risky assets appear to be generally tilted towards the more illiquid risky asset, and are likely to subsequently shift toward the less illiquid risky asset over the investment period. ${ }^{3}$ According to the model, portfolio weights in the less illiquid risky asset are also likely to tilt away from those in the benchmark portfolio significantly more than are portfolio weights of the more illiquid risky asset, which suggests that a liquidity-constrained fund manager, whose portfolio allocations are no longer under her complete control, is likely to shift portfolio risk by trading on the less illiquid asset. Furthermore, fund managers have implicit incentives to distort portfolio allocations so as to increase the likelihood of future fund inflows, and explicit incentives to administer investors' savings according to their own attitudes towards risk, their (usually shorter) investment horizons, and their (eventually more favorable) participation and transaction costs. My analysis indicates that the misalignment of objectives between the investor and the fund manager can be very costly, and that these costs appear to decrease with asset illiquidity. Lastly, after comparing utilities derived under liquidity constraints, with those derived in a context without such constraints, the model proposed here indicates that the shadow costs of illiquidity appear to be larger for the delegated portfolio problem, compared 
to the direct investing one.

For ease of exposition, I confine attention to a nominal economy, a constant investment opportunity set, and a constant relative risk aversion (CRRA, hereafter) preference structure. I also focus my analysis on the simple fund flow-to-performance function used in Browne (1999) and Binsbergen, Brandt, and Koijen (2008), where flows into and out of a fund are unbounded and do not depend on the performance of the portfolio chosen by the manager, but solely on the performance of the exogenous benchmark. I recognize that an alternative and more interesting specification for this flow-to-performance function would exhibit a local convexity and would take the size of the flows into and out of the fund to depend on the fund's own performance relative to the benchmark, like the one studied in Basak, Pavlova, and Shapiro (2007), which is capped and calibrated according to the empirical estimations of Chevalier and Ellison (1997). Nevertheless, most of the main results presented in this paper hold using either of these specifications.

This work is closely related to the strand of research on risk-shifting incentives in delegated portfolio management, and the implications of benchmarking, represented on empirical grounds by Chevalier and Ellison (1997), Chevalier and Ellison (1999), and Sirri and Tufano (1998), and represented on theoretical grounds by Arora and Ou-Yang (2001), Browne (1999), Basak, Pavlova, and Shapiro (2007), Basak, Pavlova, and Shapiro (2008), and Basak and Makarov (2008). These studies describe a positive relationship between past performance relative to a given benchmark or peer group, and subsequent flows into and out of mutual funds, giving money managers, whose compensation is directly linked to the value of the assets they manage, an implicit incentive to distort portfolio allocations in order to increase the likelihood of finishing ahead of a given performance benchmark with the purpose of increasing future fund inflows. ${ }^{4}$ This study is also related to the long literature on asset liquidity and its implications for asset pricing and portfolio choice, examples of which are Longstaff (1995), Longstaff (2001), Liu and Loewenstein (2002), Liu (2004), Jang, Koo, Liu, and 
Loewenstein (2007), and Isaenko (2008). Also relevant for this study is the empirical evidence of mutual funds' preference for large liquid stocks (Falkenstein (1996)), evidence of liquidity timing by mutual fund managers (Cao, Simin, and Wang (2007)), evidence that portfolio liquidity is actively managed and chosen as a function of the multiple liquidity needs of a fund (Massa and Phalippou (2005)), and evidence that fund managers tilt their holdings more heavily towards liquid stocks when the market is expected to be more volatile (Huang (2008)).

The objective of the present work is then to integrate these blocks of literature and to provide a formal analysis of the implications of asset illiquidity in a delegated portfolio context. The paper is organized as follows. In Section 2 I describe the theoretical model setup, which includes the continuous-time economic setting in which investors and money managers decide their optimal dynamic portfolio policies. The setup includes the money managers' unconstrained problem, with and without implicit incentives, and the constrained problem, with constant and stochastic liquidity constraints. In Section 3 , I solve the model using numerical methods, and discuss its main results. Conclusions and implications for further research are presented in Section 4.

\section{Model setup}

\subsection{The financial market}

Consider two market participants. Let one be a household investor who exogenously decides to directly access the financial market and manage her savings by herself or who, alternatively, decides to hire a money manager to whom she delegates the administration of all her savings. ${ }^{5}$ Assume the money manager's fund belongs to a peer group consisting of a large number of competing funds, such that there are no incentives for strategic interactions among fund managers. ${ }^{6}$ Moreover, let these market participants have constant investment opportunities, and finite investment time horizons, $T_{i} \in[0, \infty)$, for $i \in\{I, M\}$. Let these participants take asset prices as given. 
Consider a nominal economy in which continuous and unlimited trading and shortselling are possible whenever liquidity restrictions are left out. In this economy, participants can invest in $m+1$ assets, with prices denoted by $S_{j}(t)$, for $j \in\{0,1,2, \ldots, m\}$. The first asset is a non-redundant nominal riskless money market account, which price dynamics follow the process:

$$
\frac{d S_{0}(t)}{S_{0}(t)}=r d t
$$

where $r \geq 0$ is a constant, continuously compounded interest rate. The remaining $m$ assets are non-redundant risky assets with nominal prices evolving according to the following equation:

$$
\frac{d S(t)}{S(t)}=\left(r \iota+\sigma_{s}^{\top} \Lambda\right) d t+\sigma_{s}^{\top} d Z(t)
$$

where $\iota$ is an $m \times 1$ vector of ones, $\Lambda$ denotes a $d \times 1$ vector of constant prices of risk, and $\sigma_{s}$ is a $d \times m$ matrix of constant loadings on the source of uncertainty generated by a $d$-dimensional standard geometric Brownian motion $Z(t)$.

Let $N_{0}(t)$ denote the number of units of the riskless money market account, and likewise let $N(t)$ denote the $m \times 1$ vector of units of the risky securities held by a market participant at time $t$, for $0 \leq t \leq T$. This market participant's wealth is therefore given by $W(t)=N_{0}(t) S_{0}(t)+N(t)^{\top} S(t)$, which evolves according to the following equation:

$$
d W(t)=N_{0}(t) r S_{0}(t) d t+N(t)^{\top} \operatorname{diag}[S(t)]\left[\left(r \iota+\sigma_{s}^{\top} \Lambda\right) d t+\sigma_{s}^{\top} d Z(t)\right]
$$

where $S(t)$ is an $m \times 1$ vector, and $\operatorname{diag}[S(t)]$ puts $S(t)$ on the main diagonal of an $m \times m$ matrix.

Now, take this market participant's holdings in the $m+1$ assets at each and every time $t$, to be self-financing and to be constrained to lie in the closed solvency region of:

$$
\mathscr{S}=\left\{\left(S_{0}(t), S(t)\right) \in \mathbb{R}^{m+1}: N_{0}(t) S_{0}(t)+N(t)^{\top} S(t)>0\right\}
$$

for all $\mathrm{t}$, and $0 \leq t \leq T$. 
Take the fund manager's compensation to be proportional to the value of the assets under her administration, and to be due at the investment horizon. Consider a fund manager whose performance is measured relative to the value of a self-designated benchmark, $Y(t) .{ }^{7}$ Assume this benchmark is a reference portfolio of risky and riskless assets which can be replicated by the fund manager. Let the benchmark evolve according to the process:

$$
d Y(t)=Y(t)\left[\left(r+\beta(t)^{\top} \sigma_{s}^{\top} \Lambda\right) d t+\beta(t)^{\top} \sigma_{s}^{\top} d Z(t)\right]
$$

where the $m \times 1$ vector $\beta(t)$ given by $\beta(t)=Y(t)^{-1} \operatorname{diag}[S(t)] M(t)$, denotes the vector of weights of the risky assets on the benchmark portfolio such that the weight on the riskless money market account is given by $1-\iota^{\top} \beta(t)$. The $m \times 1$ vector $M(t)$ denotes the number of units of risky assets that make up the benchmark at time $t$, for $0 \leq t \leq T$. I consider both a continuously rebalanced (active) benchmark, where $\beta(t)$ is set to be constant, and is determined at time $t=0$, and a buy-andhold (passive) benchmark portfolio, where $M(t)$ is set to be constant, and where $\beta(t)$ becomes rather random. Note that by "self-designated benchmark" I do not mean that vector $\beta(t)$ should be included as a control in the manager's problem from which optimal performance benchmarks are derived (e.g. Binsbergen, Brandt, and Koijen (2008)). Note that this work is also not concerned about how the incentive to improve fund inflows could drive the fund manager to strategically mismatch her fund benchmark, as empirically illustrated in Sensoy (2008). Instead, here my solo focus is on how a fund manager allocates and manages resources to achieve investment objectives, given the manager's chosen performance benchmark. The benchmark is assumed to satisfy the manager's participation constraint.

Note that this paper focuses on the description of the continuous-time optimal control problem of the fund manager, and only occasionally refers to the investor's problem, which is taken as a special case of the manager's problem. For simplicity of 
notation, subscripts $I$ and $M$ are used to indicate variables or parameters pertaining to the investor and the fund manager, respectively, only when necessary for clarity of exposition.

\subsection{The fund manager's liquidity-unconstrained problem}

As a point of reference, consider first the problem of a fund manager who is not subject to liquidity restrictions, and who derives utility from the nominal value of the lump-sum cumulative amount of assets under management at the end of his or her investment horizon, $t=T$. Since admissible allocations require $W(t)>0$, portfolio weights on risky assets are well defined and are given by the $m \times 1$ vector $\omega(t)=W(t)^{-1} \operatorname{diag}[S(t)] N(t)$, such that the remainder, $1-\boldsymbol{\iota}^{\top} \omega(t)$, denotes the portfolio weight on the money market account at time $t$, for $0 \leq t \leq T$. Plugging $\omega(t)$ into Equation (3) we get to the following functional form representing the dynamics of the value of assets under management:

$$
d W(t)=W(t)\left[\left(r+\omega(t)^{\top} \sigma_{s}^{\top} \Lambda\right) d t+\omega(t)^{\top} \sigma_{s}^{\top} d Z(t)\right]
$$

Subject to Equation (6), a fund manager guided by CRRA preferences, dynamically allocates the fund's assets valued initially at $W(0)$ among a money market account and $m$ risky assets, by choosing a vector of controls $\omega(t)$, so as to solve:

$$
J(W, t)=\sup _{\omega(t)} E_{t}\left\{\frac{[W(T) \phi(T)]^{1-\gamma}}{1-\gamma}\right\}
$$

where $\gamma>0$, and $\gamma \neq 1$, denotes the manager's coefficient of relative risk aversion, and $\phi(T)$ denotes the rate at which funds flow into $(\phi(T)>1)$ or out $(\phi(T)<1)$ of the fund at the terminal date, depending on the fund's performance relative to a given benchmark. ${ }^{8}$ I assume that the fund manager's investment horizon, $T$, coincides with the date of fund flows, and that fund flows are nontradeable at that date. ${ }^{9}$ 


\subsubsection{Optimal portfolio policies without benchmarking incentives}

Absent benchmarking considerations, in which case $\phi(t)=1$, and under regularity conditions on the value function, the Hamilton-Jacobi-Bellman Partial Differential Equation (HJB PDE, hereafter) representing the problem described above, suppressing time indicators, is given by:

$$
J_{t}+r W J_{W}+\sup _{\omega}\left\{W J_{W}\left(\omega^{\top} \sigma_{s}^{\top} \Lambda\right)+\frac{1}{2} W^{2} J_{W W}\left[\omega^{\top}\left(\sigma_{s}^{\top} \sigma_{s}\right) \omega\right]\right\}=0
$$

with terminal condition $J(W, T)=[1 /(1-\gamma)] W(T)^{1-\gamma}$. The corresponding optimal portfolio allocations on risky assets are given by the $m \times 1$ vector:

$$
\omega^{*}(t)=\frac{1}{\gamma}\left(\sigma_{s}^{\top} \sigma_{s}\right)^{-1} \sigma_{s}^{\top} \Lambda
$$

with the remainder, $1-\boldsymbol{\iota}^{\top} \omega^{*}(t)$, invested in the money market account. In this unconstrained liquidity setting, if $\Lambda<0_{m \times 1}$, then $\omega^{*}(t)<0$, the money manager chooses to hold a short position in risky assets. Likewise, if $\Lambda=0_{m \times 1}$, then $\omega^{*}(t)=0$, and if

$\Lambda>\gamma\left(\sigma_{s}^{\top}\right)^{-1}\left(\sigma_{s}^{\top} \sigma_{s}\right) \iota$, then $\omega^{*}(t)>1$, and the money manager chooses to hold a leveraged position in risky assets. Moreover, this is so in a complete market setting, where $\sigma_{s}$ is invertible, and where $\left(\sigma_{s}^{\top} \sigma_{s}\right)^{-1}=\sigma_{s}^{-1}\left(\sigma_{s}^{\top}\right)^{-1}=\sigma_{s}^{-1}\left(\sigma_{s}^{-1}\right)^{\top}$ is possible. Given that $\sigma_{s}$ is assumed to be constant, these optimal investment strategies are independent of the investment horizon, as shown in Merton (1969). Such myopic allocations require continuous trading, and clearly $N^{*}(t)=\gamma^{-1} W(t) \operatorname{diag}[S(t)]^{-1}\left(\sigma_{s}^{\top} \sigma_{s}\right)^{-1} \sigma_{s}^{\top} \Lambda$ is of unbounded variation. Hence, after plugging (9) into (6), to solve the resultant stochastic differential equation, and plugging the solution then into (7), and after linearizing the term involving the Wiener process before placing the expectation operator in front of it, the utility derived by the fund manager, as a result of implementing these 
unconstrained optimal policies, is given by:

$$
J(W, t)=\frac{W(t)^{1-\gamma}}{1-\gamma} \exp \left\{\left[r+\frac{1}{2 \gamma} A_{1}\right](1-\gamma) \tau\right\}
$$

where $A_{1}=\Lambda^{\top} \sigma_{s}\left(\sigma_{s}^{\top} \sigma_{s}\right)^{-1} \sigma_{s}^{\top} \Lambda$, and $\tau=T-t$. This complete solution to the manager's liquidity-constrained problem coincides with that of the investor whenever any explicit incentives are left out. The fund manager has explicit incentives to administer the investor's savings according to her own attitude towards risk, her (usually shorter) investment horizon, and her (eventually more favorable) participation and transaction costs. The implications of these explicit incentives are considered in Section 3.

\subsubsection{Optimal portfolio policies with benchmarking incentives}

In the presence of benchmarking incentives, a fund manager experiences money flows into and out of her fund at a rate $\phi(T)$, depending on the manager's portfolio performance, at time $T$, relative to a benchmark chosen (exogenously) at time $t=0$. For ease of exposition, in this paper I focus the analysis on the results from a fund flow-toperformance function that is in line with Browne (1999), and Binsbergen, Brandt, and Koijen (2008), and according to which fund flows do not depend on the manager's own portfolio performance, but solely on the absolute performance of an exogenous benchmark. In this case, the flow-performance function is given by $\phi(T)=1 / Y(T)$, for a $Y(t)$ that evolves according to Equation (5). The convenience of this configuration is that it allows the derivation of a closed form solution for the optimal portfolio policies, whenever trading restrictions are left out, which helps with the intuition of the results I present in Section 3.2. If we let $X(T)=W(T) \phi(T)$, and we apply Ito's rule, we arrive at the dynamics of $X(t)$, for $\phi(t)=1 / Y(t)$, as follows:

$$
d X(t)=X(t)[\omega(t)-\beta(t)]^{\top}\left[\left(\sigma_{s}^{\top} \Lambda-\left(\sigma_{s}^{\top} \sigma_{s}\right) \beta(t)\right) d t+\sigma_{s}^{\top} d Z(t)\right]
$$


and, under regularity conditions on the value function, suppressing time indicators, and given a continuously rebalanced benchmark, the HJB PDE for this problem is given by:

$$
\begin{aligned}
& \sup _{\omega}\{\left.X J_{X}\left(\omega^{\top} A_{2}\right)+\frac{1}{2} X^{2} J_{X X}\left[\omega^{\top}\left(\sigma_{s}^{\top} \sigma_{s}\right)(\omega-2 \beta)\right]\right\}- \\
&-X J_{X}\left(\beta^{\top} A_{2}\right)+\frac{1}{2} X^{2} J_{X X}\left[\beta^{\top}\left(\sigma_{s}^{\top} \sigma_{s}\right) \beta\right]+J_{t}=0
\end{aligned}
$$

where $A_{2}=\sigma_{s}^{\top} \Lambda-\left(\sigma_{s}^{\top} \sigma_{s}\right) \beta$, and with terminal condition $J(X, T)=[1 /(1-\gamma)] X(T)^{1-\gamma}$. Hence, when the performance of the fund manager is measured relative to an exogenous benchmark, the manager's optimal portfolio is given by:

$$
\omega^{\#}(t)=\frac{1}{\gamma}\left(\sigma_{s}^{\top} \sigma_{s}\right)^{-1} \sigma_{s}^{\top} \Lambda+\left(1-\frac{1}{\gamma}\right) \beta(t)
$$

which is independent of the investment horizon when our money manager chooses to be compared to a continuously rebalanced benchmark, in which case $\beta(t)$ is set to be constant. When the money manager chooses to have her performance be measured against a (passive) buy-and-hold benchmark, her optimal portfolio weights, as give by Equation (13), become rather time-varying, because the vector of weights on the benchmark portfolio becomes a moving target, for a money manager who chooses active investing. This optimal portfolio policy contains an actively managed component and a herd component, the latter mimicking the benchmark against which the manager's performance is measured. Note that, in fact, the manager will tend to track the benchmark more and more closely as her risk aversion increases. Clearly, when $\gamma>1$, if $\beta(t)>\omega^{*}(t)$, then the manager has an incentive to increase risk exposure. On the contrary, if $\beta(t)<\omega^{*}(t)$, the manager has an incentive to herd and decrease risk exposure. In either case, the dynamics of the optimal number of units held by the fund manager on risky assets, $N^{*}(t)$, is that of a process of unbounded variation, where both unlimited leveraged and short positions are admissible. This assumption 
of continuously and unlimited trading, which has been common in delegated portfolio management literature, is going to be relaxed in Section 2.3 .

The solution to the derived utility of the terminal value of assets under management when the fund manager chooses a continuously rebalanced exogenous benchmark against which to measure performance, is given by:

$$
J(X, t)=\frac{X(t)^{1-\gamma}}{1-\gamma} \exp \left\{\frac{1}{2 \gamma}\left[A_{1}-A_{3}-\beta(t)^{\top} A_{2}\right](1-\gamma) \tau\right\}
$$

where $\beta$ is constant, $A_{3}=\Lambda^{\top} \sigma_{s} \beta(t)$, and $\tau=T-t$. No such explicit solution exists for the case in which the fund manager chooses to have his performance measured relative to (value-weighted) buy-and-hold benchmark, because in that case $\beta(t)$ is a rather stochastic variable which distribution is unknown.

Alternative specifications are investigated in Basak, Pavlova, and Shapiro (2007), in which flow-to-performance functions exhibit a local convexity and take the size of the flows into and out of the manager's fund to depend on the fund's own performance relative to the benchmark. However, given that the main results of this paper hold for either of these specifications, I focus my analysis on the simpler and more intuitive case where $\phi(T)=1 / Y(T)$.

\subsection{The fund manager's liquidity-constrained problem}

In practice, fund managers face multiple constraints. Sudden liquidity dry-ups, like the one that accompanied the 2007-08 meltdown in sub-prime lending, result in fund managers finding themselves forced to sit on their hands for long periods of time, unable to deal in any size in shares of even the more liquid large-cap companies. ${ }^{10}$ As a result, managers loose control over their portfolio allocations, which potentially puts their short-term performance records (not to mention their jobs) in jeopardy.

Thus, let the fund manager choose, at time $t=0$, an $m \times 1$ portfolio vector $\omega(0)$, which she will want to revise later on if she chooses to actively invest. However, for 
$t>0$, take the size of the money manager's trades each period, for a given cost, to be out of her complete control, and restricted to lie in a bounded interval. Specifically, and in parallel with Longstaff (2001), assume that the dynamics of the number of units of risky assets that the money manager can hold each time, is given by:

$$
d N(t)=\eta(t) d t
$$

where $\eta(t)$ is an $m \times 1$ vector, $-\infty<-\psi(t) \leq \eta(t) \leq \psi(t)<\infty$ and $\psi(t) \geq 0$. This specification captures the aspect of depth in financial markets, which I allow to be asset-

specific. $^{11}$ I also allow it to be either constant or time-varying. In this context, the dynamics of the value of a fund's assets under management is given by the expression:

$$
d W(t)=r W(t) d t+N(t)^{\top} \operatorname{diag}[S(t)]\left[\sigma_{s}^{\top} \Lambda d t+\sigma_{s}^{\top} d Z(t)\right]
$$

which will coincide with the budget constraint of an individual investor, in case we leave out any explicit and implicit incentives provided to the fund manager by her compensation scheme, risk appetite, or investment horizon. Thus, when liquidity is constrained, the manager can find herself in a situation where portfolio allocations are no longer under her control, and it can take a long time for her to "trade out of mistakes" in less liquid assets, which may very well lead to bankruptcy. Therefore, in order to guarantee the solvency of the fund, the manager has to abstain from taking leveraged positions or short extensions in the available risky assets. Accordingly, as in Longstaff (2001), in order for portfolio policies to be admissible, optimal controls $\omega(0)$ and $\eta(t)$ need to be such that $0 \leq \omega(t) \leq 1$, and $0 \leq 1-\iota^{\top} \omega(t) \leq 1$, for all $0 \leq t \leq T$.

\subsubsection{Constant liquidity constraints}

Consider first the case in which the liquidity constraint, as measured by the value of the parameter $\psi(t)$, is set to be constant, $\psi(t)=\alpha$, for all $0<t \leq T$. As a result, and 
because Equation (16) is now a function of $W(t), N(t)$, and $S(t)$, the problem of our CRRA fund manager, who decides on an initial allocation of capital among $m$ risky assets, $\omega(0)$, and a money market account, $1-\iota^{\top} \omega(0)$, as well as on the subsequent revisions of that initial portfolio, as denoted by the $m \times 1$ vector of continuous controls $\eta(t)$, is stated as:

$$
J(W, N, S, t)=\sup _{\omega(0), \eta(t)} E_{t}\left\{\frac{[W(T) \phi(T)]^{1-\gamma}}{1-\gamma}\right\}
$$

subject to the budget constraint (16). Under regularity conditions on the value function, absent benchmarking incentives, $\phi(T)=1$, and suppressing time indicators, the HJB PDE for this problem is given by:

$$
\begin{array}{r}
J_{t}+J_{W} r W+J_{W}\left[N^{\top} \operatorname{diag}[S]\left(\sigma_{s}^{\top} \Lambda\right)\right]+\frac{1}{2} J_{W W}\left[N^{\top} A_{4} N\right]+ \\
+J_{S}\left[\operatorname{diag}[S]\left(r \iota+\sigma_{s}^{\top} \Lambda\right)\right]+\frac{1}{2} \operatorname{tr}\left[J_{S S} A_{4}\right]+J_{W S}\left[A_{4} N\right]+\sup _{\eta}\left\{\eta^{\top} J_{N}\right\}=0
\end{array}
$$

with terminal condition $J(W, N, S, T)=[1 /(1-\gamma)][W(T) \phi(T)]^{1-\gamma}$, where $J_{S}$ and $J_{W S}$ are $1 \times m$ vectors, $J_{N}$ is an $m \times 1$ vector, $J_{S S}$ is an $m \times m$ matrix, and $A_{4}=$ $\operatorname{diag}[S]\left(\sigma_{s}^{\top} \sigma_{s}\right) \operatorname{diag}[S]$. In this case, because $\eta(t)$ is constrained, the HJB PDE is optimized by choosing $\eta(t)$ so as to maximize the term $\eta^{\top} J_{N}$ for a given initial portfolio vector $\omega(0)$. Therefore, the constrained money manager follows a bang-bang control policy, according to which she chooses either $\eta=\alpha$ if $J_{N}>0$, or $\eta=-\alpha$ if $J_{N}<0$, or $\eta=0$ if $J_{N}=0$, as long as it is guaranteed that $W(t)>0$, and the trading strategies are admissible, meaning $N_{0}(t) \geq 0, N(t) \geq 0$, and $N_{0}(t)+\iota^{\top} N(t)>0$, for all $0 \leq t \leq T$. Absent benchmarking incentives, the formal solution to the fund manager's derived utility is given by:

$$
J(W, N, S, t ; \omega(0))=\frac{W(t)^{1-\gamma}}{1-\gamma} E_{t}\left[\exp \left\{\int_{t}^{T} A_{5}(u) d u+\int_{t}^{T} A_{6}(u) d Z(u)\right\}\right]
$$


where $A_{5}(t)=r(1-\gamma)+A_{6}(t)\left(\Lambda-(1 / 2) \sigma_{s} \omega(t)\right)$, and $A_{6}(t)=(1-\gamma) \omega(t)^{\top} \sigma_{s}^{\top}$. Note that the portfolio weight vector $\omega(t)$ enters the derived utility function both linearly and quadratically, which means that liquidity restrictions introduce a second layer of mean-variance analysis into the manager's problem.

This problem coincides with the problem of a liquidity-constrained investor, if we also leave out the fund manager's explicit incentives. In Section 3 , I use numerical techniques to solve this optimization problem, as well as the problem that accounts for the manager's benchmarking incentives, as discussed in Section 2.2.2. In particular, I use the methodology suggested in Longstaff (2001). It consists of an application of the Least-Squares Monte Carlo algorithm, proposed by Longstaff and Schwartz (2001). Succinctly, it involves replacing the conditional expectation function in (19) by its orthogonal projection on the space generated by a finite set of basis functions of the values of the state variables that are part of the manager's problem. Next, from that explicit functional approximation, we can then solve for the optimal control variable $\eta(t)$, as defined above, for any given $\omega(0)$. Portfolio weights held in risky assets are then easily retrieved, for each time $t$, for $0 \leq t \leq T$, from the relation:

$$
\omega_{j}(t)=\omega_{j}(0)+\int_{0}^{t} \frac{S_{j}(u)}{W(u)} \eta_{j}(u) d u
$$

where $\eta_{j}(0)=0$, and $j \in\{1,2, \ldots, m\}$.

\subsubsection{Time-varying liquidity constraints}

Existing literature provides evidence of liquidity timing by mutual fund managers (Cao, Simin, and Wang (2007)), evidence that portfolio liquidity is actively managed and is chosen as a function of the multiple liquidity needs of a fund (Massa and Phalippou (2005)), and also evidence that fund managers tilt their holdings more heavily towards liquid stocks when the market is expected to be more volatile (Huang (2008)). Moreover, according to Acharya and Pedersen (2005), liquid funds are likely to overperform 
in illiquid periods, and to underperform during liquid periods. What's more, stock market downturns have been showing that liquidity has a way of suddenly drying up when it is needed the most, has commonality across assets (Chordia, Roll, and Subrahmanyam (2000)), is related to volatility, and co-moves with the market.

In order to capture some of these aspects of market liquidity, including the "flightto-quality" incentive induced by the liquidity uncertainty in the risky assets' market, consider the following mean-reversion process:

$$
d \alpha(t)=K(\pi-\alpha(t)) d t+\sigma_{\alpha}^{\top} d Z(t)
$$

where $\alpha(t)$ and $\pi$, are $m \times 1$ vectors, $K$ is an $m \times m$ diagonal matrix of speed of reversion parameters, and $\sigma_{\alpha}$ is a $d \times m$ matrix of loadings on the sources of uncertainty, generated by the same $d$-dimensional geometric Brownian motion used in previous sections, $Z(t)$. I then allow the fund manager to be able to hedge against liquidity risk. Note, however, that we need the stochastic liquidity parameter $\psi(t)$, as defined above, to assume only positive values, and to have a long-run equilibrium level denoted by $\theta$. In this case, an adequate mean-reverting model for $\psi(t)$ can be represented by:

$$
\psi(t)=\exp \left\{\alpha(t)-\frac{1}{2}\left(\iota-\frac{1}{2}\left[\exp \{-2 K t\} K^{-1}\right] D_{\alpha}\right)\right\}
$$

where $\psi(t)$ is an $m \times 1$ vector, $K^{-1}$ is the inverse matrix of $K$, and $D_{\alpha}$ is an $m \times 1$ vector that contains the diagonal of the matrix $\left(\sigma_{\alpha}^{\top} \sigma_{\alpha}\right)$. The long-run equilibrium level for $\psi(t)$ is related to the equilibrium level for $\alpha(t)$, and is given by the relation $\theta=\exp \{\pi\}$. Here, like in Section 2.3.1, the money manager's optimal portfolio strategy is to trade as much as possible, whenever possible. 


\section{Numerical results and discussion}

Let the investor and the fund manager trade in two risky assets $(m=2)$, which may have distinct degrees of liquidity. We could think of one of those risky assets to be a liquid well-known publicly traded large-cap stock, while the other would be, for instance, real estate or a small-cap stock from an emerging economy. I addition, let uncertainty be generated by a two-dimensional Brownian motion $(d=2)$, such that the price dynamics for these two risky assets is to include the following $2 \times 2$ matrix of loadings on the sources of risk:

$$
\sigma_{s}=\left(\begin{array}{ll}
\sigma_{11} & \sigma_{21} \\
\sigma_{12} & \sigma_{22}
\end{array}\right)
$$

where the term $\sigma_{j k}$ denotes the loading that asset $j$ puts on the source of risk $k$. From 23 we get that the variance of asset $j$ is given by $\sigma_{j}^{2}=\sigma_{j 1}^{2}+\sigma_{j 2}^{2}$ and the correlation between the two assets is given by $\rho=\left(\sigma_{11} \sigma_{21}+\sigma_{12} \sigma_{22}\right) /\left(\sigma_{1} \sigma_{2}\right)$. In addition, let the

$2 \times 1$ vector of expected returns for this pair of risky assets be given by $\mu=r \iota+\sigma_{s}^{\top} \Lambda$. The numerical results in this section are based on 100,000 runs and 20 time steps per year. Investment horizons $T_{i}$, for $i \in\{I, M\}$, are expressed in years. Initial prices of assets (risky and riskless) are set to unity, such that $S_{j}(0)=1$, where $j \in\{0,1,2\}$. Furthermore, let the riskless money market account earn a constant riskless interest rate $r=0.02$. Bear in mind that, when looking at the results presented in the sections that follow, we should focus on their comparative statics and predictions, not on the reality of their assumptions.

\subsection{Analysis of illiquidity and explicit incentives}

The fund manager has an explicit incentive to administer the investor's savings according to her own attitude towards risk, her (usually shorter) investment horizon, and her (eventually more favorable) participation and transaction costs. In this section, I 
assess the economic significance of these explicit incentives, in particular the case in which the appetites for risk diverge between the investor and the manager, and to what extent the presence of liquidity constraints affects its likely outcome.

\subsubsection{The case of symmetric asset liquidity constraints}

First, consider the case where the two risky assets are identical in every respect, including their liquidity characteristics. Table 1 reports the optimal initial portfolio weights for the unconstrained, and the constrained liquidity cases, $\omega_{j}^{u}(0)$, and $\omega_{j}^{c}(0)$, respectively, for different values of $T_{i}, \rho, \sigma_{j}$, and $\gamma_{i}$, when in the absence of benchmarking incentives $(\phi(T)=1)$. Take the two risky assets to be identical in every respect, so we can isolate the effects of the misalignment of incentives between the investor and the fund manager. Therefore, I set both risky assets to have the same expected return, $\mu_{j}=0.10$, and to be non-tradeable $\left(\alpha_{j}=0\right)$, for $t>0$, throughout the period $T_{i}$. In terms of comparative statics, these results show that, under liquidity constraints, there is "flight-to-quality" through which either the investor or the fund manager choose to hold fewer of the riskier assets and more of the safest one. This lower total initial risk exposure is due to hedging demands against the portfolio weights uncertainty measured by $C S V_{j}$, at $t=T_{i}$, which is the cross-sectional variation of the simulated portfolio weights for each asset $j$ and represents the extent to which portfolio weights are out of the control of market participants when liquidity is constrained. As a result, under liquidity constraints, market participants need to care about not only the mean and variance of the risky assets, but also the mean and variance of the portfolio weights, which are out of their complete control. For the set of input parameters I consider, note that $\mathrm{CSV}_{j}$ increases with $\sigma_{j}$ for independent and negatively correlated risky assets, while it decreases for positively correlated risky assets. Not unexpectedly, constrained portfolio weights' variation increases with the investment horizon. These simulated

variations range from .0105 (for $\rho=0.5, \gamma_{i}=10, \sigma_{j}=0.5$, and $T_{i}=1$ ), to .2258 (for $\rho=0.5, \gamma_{i}=1, \sigma_{j}=0.5$, and $T_{i}=1$ ), while they are all null for the unconstrained 
portfolio weights, by construction. To trade-off the expected value of $\omega_{j}^{c}(t)$ with its variation is also part of the problem of a liquidity constrained market participant. Note also that, when the unconstrained investor holds a leveraged position, the constrained one restricts her portfolio weights to lie in the interval $0 \leq \omega_{1}^{c}(0)+\omega_{2}^{c}(0) \leq 1$, to prevent against insolvency. Because the wealth of the investor or the value of the fund's assets are processes bounded below by zero, and given that, under liquidity constraints, returns of each risky asset cannot be replicated by those of the remaining assets in the portfolio, endogenously the market participants cannot borrow to invest more in risky assets, because the price of the illiquid assets can quickly fall and it would not be possible to sell enough of these assets to guarantee positive terminal wealth. This one dimension of liquidity is generally referred to as funding liquidity, which has to do with the availability of credit or the ease with which the investor and the manager an borrow or take on leverage. Note that this funding illiquidity was generated endogenously in this model by the market illiquidity, which is the ease with which market participants can transact, or the ability of markets to absorb large purchases or sales without much effect on prices.

Lastly, Table 1 also reports the number of basis points we would have to discount the prices of the identical risky assets so as to make the investor or the fund manager indifferent between holding the constrained portfolio, and the constrained one. These illiquidity discounts can also be thought of as the extra premiums that one would require for holding an illiquid asset instead of a perfectly liquid one. For this set of parameters, illiquidity discounts (ID) increase with $T_{i}$, and decrease with $\gamma_{i}, \rho$, and $\sigma_{j}$. They range from 1.23 to $1,380.80$ basis points. In particular, for $T_{i}=2, \sigma_{j}=0.3$, $\rho=0$, and $\gamma_{i}=1$, the price of the identical risky assets would have to be discounted by $2.87 \%$ so as to compensate the investor for holding a buy-and-hold portfolio, instead of one he or she could rebalance without restrictions. Not surprisingly, the largest discounts occur when endogenous constraints on leverage are binding. Note also that, when the risky assets' volatility is decreased from $\sigma_{j}=0.5$ to $\sigma_{j}=0.3$, two opposite 
forces influence the value of the discounts for the lack of liquidity. On the one hand, when assets' volatility decreases, unconstrained initial portfolio weights increase and borrowing constraints bind more quickly, which leads to increases in discounts in order to compensate for funding illiquidity. On the other hand, a decrease in assets' return volatility also makes it less likely that constrained portfolios will deviate from the unconstrained ones, which can lead to decreases in pricing discounts for illiquidity.

\subsubsection{The case of asymmetric asset liquidity constraints}

Consider now the case in which we relax the trading constraint on one of the assets. Let the maximum number of shares of asset 2 , that can be traded per year, be $\alpha_{2}=0.10$, while keeping $\alpha_{1}=0$. Table 2 reports the optimal initial portfolio weights for the unconstrained, and the constrained liquidity cases, $\omega_{j}^{u}(0)$, and $\omega_{j}^{c}(0)$, respectively, for $T_{i}=1, \sigma_{j}=0.5$, and different values of $\rho$, and $\gamma_{i}$, where benchmarking incentives are still left out $(\phi(T)=1)$. Because the risky assets are not identical in terms of tradability anymore, in this table I show the optimal portfolio allocations, with and without constraints, separately for each of the risky assets. The main result of this table is that, when using two identical risky assets with different liquidity constraints, the investor and the manager's initial portfolios are likely to be skewed towards the more illiquid asset, which is to say $\omega_{1}^{c}(0)>\omega_{2}^{c}(0)$, and that over the investment period, these portfolio allocations are likely to shift weights towards the less illiquid asset, as we can see from the values of $\mathrm{E}\left[\omega_{j}^{c}(T)\right]$ in Table 2 . We know that if these market participants were able to trade as much of these risky assets as desired, they would choose to hold the unconstrained portfolio weights, as denoted by $\omega_{j}^{u}(0)$, which are their most efficient allocations. However, under liquidity constraints, they need to hedge against the possibility that, beyond time zero, they may not be able to hold those efficient portfolio weights and at the same time they will not want to deviate too much from them. One would expect that, after relaxing the liquidity constraint on asset 2 its initial portfolio weight could now be placed closer to the unconstrained weight, 
but that is not the case. There are hedging and diversification forces simultaneously at play here in order to create this apparently counter-intuitive effect. if these market participants were to be ale to trade only on one illiquid risky asset and one riskless asset, and the liquidity constraint on that one illiquid asset was to be partially relaxed, then we would find its portfolio weight to get closer to its unconstrained weight. It is important to note, however, that in the one risky asset case, market participants have no diversification concerns. In the two risky assets case presented in this paper diversification does matter. Asset 1 is not allowed to trade beyond time zero, while asset 2 can be traded after time zero, even if in limited amounts. The price of both assets has a positive drift, which moves the mass of probability to the upside of the price movement. Therefore, it becomes likely that after time zero the market participants would want to increase their holdings of both assets, but given that they are restricted from doing that for asset 1, it makes sense to hold more of asset 1 than of asset 2 to begin with, and to hold a portfolio weight on asset 1 that is as close as possible to that they would choose in an unconstrained context. Moreover, combining the facts that asset 2 is allowed to trade beyond time zero, the market participants are likely to want to increase their holdings on asset 2 given its positive drift and, at the same time, they need to diversify their portfolios in order to reduce their idiosyncratic risks as much as possible, then they optimally choose to allocate relatively smaller fractions of capital on asset 2 to start with, and to subsequently buildup those positions over the investment period, this way expecting to minimize the costs that could arise from poor diversification strategies. Another important aspect of this problem is that, under liquidity constraints, market participants have concerns about portfolio weights' uncertainty. When there are two risky assets with different liquidity constraints, one should expect portfolio weight uncertainty to be higher for the more illiquid asset 1 than for asset 2, not only because of the price volatilities of assets 1 and 2, but also because every time one trades asset 2 , that affects the portfolio weight of asset 1 . So, one would expect the market participants to take advantage of their ability to trade 
asset 2 to somehow decrease the uncertainty of the portfolio weight on asset 1 , and this way increase their overall derived utilities.

Note that the ratio of the more liquid asset initial portfolio weight, $\omega_{2}^{c}(0)$, to the one for the less liquid asset, $\omega_{1}^{c}(0)$, decreases monotonically with $\gamma_{i}$, meaning that, a more risk averse investor or money manager optimally chooses to hold relatively more of the less liquid asset. The ratio $\omega_{2}^{c}(0) / \omega_{1}^{c}(0)$ can be thought of as a measure of the level of portfolio liquidity, and Table 2 shows that the optimal initial portfolio liquidity decreases, in general, with the correlation of assets' returns. It also shows that these initial optimal portfolios shift liquidity levels over the investment period. The variable $E\left[\omega_{j}^{c}(T)\right]$ denotes the expected value of the constrained portfolio weights at time $t=T_{i}$. Note that $E\left[\omega_{2}^{c}(T)\right]$ is generally larger than $\omega_{2}^{c}(0)$ by, approximately, $\alpha_{2}=0.10$, the maximum number of shares of asset 2 that can be traded per year. Note also that the cross-sectional variation of $\omega_{2}^{c}(T)$, given by $\mathrm{CSV}_{2}$, is generally larger than the one we discussed above for Table 1, where asset 2 could not be traded, while $\mathrm{CSV}_{1}$ remains of the same kind as in Table1. Thus, the constrained money manager, in trading off the expected value of $\omega_{2}^{c}(T)$ against its variation, does so by taking much smaller initial positions and by trading asset 2, so as to keep the non-tradeable asset 1's portfolio weights' expected value, and variation, under control. However, the optimal utility levels that an investor/manager attains when actively trading asset 2 , turn out to be lower than those she would obtain under a passive buy-and-hold strategy as the one shown in Table 1. Table 2 shows the variable $\mathrm{CSV}_{W}$, which denotes the cross-sectional variation of the value of assets under management at $t=T_{i}$. Generally, these variations of $W(T)$ are larger when trading for asset 2 is allowed than when it is not.

I cannot directly assign to each of these two assets the responsibility for the total cost of the illiquidity effect. Therefore, in Table $2 \mathrm{I}$ report instead the total illiquidity cost (IC), which denotes the percent (measured in basis points) of the investor's (or, likewise, the manager's) initial wealth, that one would have to give her in order to compensate her for holding a liquidity constrained portfolio, instead of a portfolio that 
she could revise with no restrictions. Note that, as expected, IC increases when shortselling constraints bind.

For brevity, I do not tabulate the simulation results for the case where, leaving everything else constant, I let $T_{i}=2$, or alternatively, I let $\sigma_{j}=0.3$. Succinctly, for longer investment horizons, initial portfolio weights decrease substantially, but illiquidity costs, and portfolio value variations, increase drastically. For instance, when $\rho=0$, and $\gamma_{i}=10$, then $\mathrm{IC}=2.022 \%, \mathrm{CSV}_{2}=0.1254$. If, alternatively, I let $\sigma_{j}=0.3$, then illiquidity costs increase dramatically for $\gamma_{i}=1$, while they decrease for $\gamma_{i}>1$, which is the result of having endogenous borrowing constraints to bind. Differently, when I keep all the same parameters used in Table 2 except that I also allow asset 1 to trade during the investment period, with $\alpha_{1}=0.10$, then the assets return to identical, as in Table 1, but optimal initial portfolio risk exposure decreases, while illiquidity discounts rise.

\subsubsection{The case of divergence in appetites for risk}

We observe the SEC regularly advising investors to carefully read fund prospectus and shareholder reports, to learn about its investment strategy and the risks it takes to achieve its returns, so that these risks can be factored in and be tested for consistency with the investor's financial goals and risk tolerance. In fact, significant misalignments of incentives can be derived from the extensive differences in appetites for risk between investor and fund manager. Figure 1 reveals the shape of the shadow costs associated with this particular explicit incentive, as a function of both the investor's and the money manager's risk appetites. Note that it is asymmetric, that the costs of delegation are the lowest when the manager's risk aversion parameter is equal to that of the investor, and the highest when the manager exhibits lower risk aversion than the investor. Table 3 reports these costs for investment horizons $T_{i}=1$, and where input

parameter values are as those in Table 1. These costs are expressed as the percent of wealth the suboptimal investor would be willing to give away in return for being 
allowed to follow the optimal strategy. Panel A reports the shadow costs for the unconstrained liquidity case. Panel B reveals the results for the case where liquidity is totally constrained $\left(\alpha_{j}=0\right)$. Not unexpectedly, when investor and manager have the same attitude towards risk, given implicit incentives are left out, the money manager is acting in the best interest of the investor and, as a result, no losses are derived from this delegated portfolio relationship. However, in case of divergence in risk attitudes, utility costs can become very significant. These costs range from $0.08 \%$ to $250.33 \%$ of the investor's initial wealth, for the unconstrained liquidity case, while they range from $0 \%$ to $32.66 \%$ in the constrained liquidity case. Largest costs occur for higher values of $\gamma_{I}$, and lower values of $\gamma_{M}$, which is what we should find, professional money managers to be much less risk averse than fund investors. What is interesting to see in these results is that utility costs become significantly lower when in the presence of liquidity constraints. This has to do with the endogenous leveraging constraints, and hedging demands, which restrain portfolio weights to fall into a closed limited set of values, in order to prevent for bankruptcy. These costs significantly increase with the investment horizon $T_{i}$. When the investment horizon increases to 2 years, utility losses derived from the difference in appetites for risk between the investor and the money manager, for the same parameter values as in Table 3 , range from $0.17 \%$ (for $\gamma_{I}=5$, $\gamma_{M}=10, \rho=0.5$, and $\sigma_{j}=0.5$ ) to $709.27 \%\left(\right.$ for $\gamma_{I}=10, \gamma_{M}=1, \rho=-0.5$, and $\sigma_{j}=0.3$ ), in the unconstrained liquidity case, while they range from $0 \%$ (for $\gamma_{I}=1$, $\gamma_{M}=2, \rho=-0.5$, and $\left.\sigma_{j}=0.3\right)$ to $59.59 \%\left(\right.$ for $\gamma_{I}=10, \gamma_{M}=1, \rho=-0.5$, and $\left.\sigma_{j}=0.5\right)$, in the constrained liquidity case.

For brevity, I do not tabulate either the results for $T_{i}=2$, or the results for $\alpha_{1}=0$ and $\alpha_{2}=0.10$. When I let the maximum number of shares of asset 2 , that can be traded per year, be $\alpha_{2}=0.10$, then utility losses for a constrained investor whose risk appetite may not be consistent with that of the fund manager to whom she delegates the management of all her savings, are generally reduced. They range from $0.04 \%$ to $32.35 \%$, when $\sigma_{j}=0.5$. For instance, when $\gamma_{M}=10, \gamma_{I}=2, \rho=0$, and $\sigma_{j}=0.5$, and 
$T_{i}=1$, the utility loss is equal to $0.63 \%$, instead of $0.74 \%$. These utility costs increase for longer investment horizons and for lower asset return volatilities, everything else constant.

\subsubsection{Implications of time-varying liquidity constraints}

Furthermore, I examine the implications of allowing marketability bounds to follow a stochastic process like the one described by expression $(22)$, in Section 2.3.2. Table 4 reports optimal initial investment policies that the investor, and the fund manager alike, would choose, absent benchmarking incentives $(\phi(t)=1)$, for the case where asset 2 is allowed to trade throughout the year, and the following parameter values: volatility of the marketability bound for asset $2, \sigma_{\alpha_{2}}=0.2$, speed of reversion $\kappa_{2}=0.1$ (where $\kappa_{h}$ denotes the $h^{\text {th }}$ element of the diagonal matrix $K$ ), initial value $\psi_{2}(0)=0.1$ (annualized), long-run equilibrium levels $\theta_{2}=0.1$ (annualized), in Panel A, $\theta_{2}=0.2$, in Panel $\mathrm{B}, \sigma_{j}=0.5$, and $T_{i}=1$. Succinctly, these results suggest that illiquidity costs slightly increase when we allow marketability to be stochastic, and increase more for larger long-run equilibrium levels of liquidity. In addition, cross-sectional variations for $\omega_{2}^{c}(T)$ rise, while they remain roughly level for $\omega_{1}^{c}(T)$. Furthermore, Table 4 also reports estimates for the parameter $\lambda_{j 2}$, which denotes the simulated average timeseries correlation coefficients between $\omega_{j}^{c}(t)$ and the stochastic $\psi_{2}(t)$, for $j \in\{1,2\}$. The values for these coefficients suggest that swings in asset 2's marketability are directly accompanied by $\omega_{j}^{c}(t)$, progressively more closely the more risk tolerant is the investor/manager, and the larger the equilibrium level $\theta$. Finally, on the whole, shadow costs of explicit incentives, under stochastic liquidity, generally decrease.

\subsection{Analysis of illiquidity and benchmarking incentives}

In this section, I investigate the case in which the fund manager derives her utility not just from the value of assets under management, but the ratio of this to the value of 
an exogenous benchmark. Assume that both investor and fund manager guide their portfolio allocations by similar risk appetites, investment horizons, and participation constraints.

\subsubsection{Implications of benchmarking for buy-and-hold policies}

Table 5 reports optimal initial portfolio weights a money manager would choose in case her fund's performance was to be measured against the performance of a continuously rebalanced benchmark portfolio, $Y(t)$, for $\beta_{j}(t)=0.5$, with a flow-to-performance function $\phi(T)=1 / Y(T)$ (e.g. Browne (1999), Binsbergen, Brandt, and Koijen (2008)), where risky assets are set to be identical in all respects, independent $(\rho=0)$, and totally illiquid $\left(\alpha_{j}=0\right)$. I assume the benchmark portfolio weights are equal for both of the risky assets so that the manager has equal incentives to load her optimal allocations on the assets that are in the benchmark. One may ask whether or not it is reasonable to assume that a performance benchmark can be composed of illiquid assets. This assumption could be justified by the ex-ante fear of fund managers about market crashes. In other words, one can assume ex-ante that some of the assets in a benchmark can become illiquid, like financials and real estate during the current subprime crisis, or the tech stocks in the internet crash. Panel A shows the results for the case where $T_{M}=1$, while Panel $\mathrm{B}$ shows the results for $T_{M}=2$. Figure 2 illustrates how the shape of the money manager's derived utility function looks like, for a particular set of parameters, and for $\phi(T)=1 / Y(T)$. Optimal initial portfolio weights are, therefore, those that attain the maximum of this function. When compared to the results in Table

1. Table 5 shows that the money manager's optimal initial portfolio policies have now an actively managed component, and an herd component. It just confirms the result of Equation (13), in Section 2.2.2, for the case where $\phi(T)=1 / Y(T)$. If we take the difference between the optimal initial portfolio weights of Table 5 , and those in Table 1. and then divide these differences by the latter values, we get a potential measure of herding demands. From these computations, it becomes clear that, generally, for 
$\phi(T)=1 / Y(T)$, herding incentives become slightly larger for the constrained liquidity case, when compared to the liquidity unconstrained one. These results show that a more and more risk averse money manager tends to choose portfolio allocations that converge more and more to the benchmark portfolio weights when $\phi(T)=1 / Y(T)$. For longer investment horizons, these results get amplified.

Table 5 also shows that cross-sectional variations of the portfolio weights, $\mathrm{CSV}_{j}$, increase in the presence of benchmarking. It also shows the simulated cross-sectional variations for the value of assets under management, and the benchmark portfolio $\left(\beta_{j}(t)=0.5\right)$, at the horizon $T_{M}$, which are denoted by $\mathrm{CSV}_{W}$ and $\mathrm{CSV}_{Y}$, respectively. These results show that, generally, $\mathrm{CSV}_{W}<\mathrm{CSV}_{Y}$, given that the benchmark is continuously rebalancing in order to preserve $\beta_{j}(t)=0.5$, while the risky assets in the manager's portfolio are totally illiquid, which makes it a buy-and-hold portfolio. Nevertheless, the tracking error of $Y, \mathrm{TE}_{Y}$, is relatively small. As a tracking error measure, I use the square root of the non-central second moment of the deviations between the money manager's portfolio and benchmark returns, which is the measure that is frequently used in practice. The tracking error for $\beta_{j}(t)$, denoted by $\mathrm{TE}_{\beta}$, appears to be significantly larger than $\mathrm{TE}_{Y}$ and decreasing with $\gamma_{M}$. As a result, illiquidity discounts (ID) for our identical illiquid risky assets, come out dramatically larger when compared to the results in Table 1, and which get amplified for longer investment horizons. Finally, Table 5 also reports the simulated probabilities that the money manager's optimal portfolio values end up below that of the benchmark, by the terminal date, $T_{M}$, for a given optimal control $\omega_{j}^{c}(0)$, which are denoted by $\mathrm{P}[W<Y]$. Bear in mind that we normalized $W(0)=Y(0)=1$. For brevity, I do not tabulate the results I obtain for $\beta_{j}(t)=0.2$, in which case the benchmark has a money market exposure of $\beta_{0}=0.6$. Obviously, in this case, the cross-sectional variations of $Y(T)$ become significantly lower, where $\mathrm{CSV}_{Y}=0.151$ for $T_{M}=1$, and $\mathrm{CSV}_{Y}=0.225$ for $T_{M}=2$. Moreover, the probabilities of under-performing the benchmark rise, despite the reductions in $\mathrm{TE}_{Y}$, and $\mathrm{TE}_{\beta}$. 
Table 6 shows the results for the case in which the benchmark is value-weighted or buy-and-hold. It shows that hedging demands for illiquidity, as measured by the difference between $\omega^{u}(0)$ and $\omega^{c}(0)$, are smaller for the case in which the benchmark is (value-weighted) buy-and-hold, when compared to those in which the benchmark is (equally-weighted) continuously rebalanced. Compared to Table 5, note that in Table 6 one extra column was added which includes information on $C S V_{u}$, the crosssectional variation of the optimal unconstrained weights, which was null for a rebalanced benchmark, but is now stochastic when using a buy-and-hold benchmark. Note that, when using a buy-and-hold benchmark, the tracking errors for $\beta_{j}$ and $Y$ decrease significantly, as well as the value of the discounts for the lack of liquidity, ID(bp), which almost vanish for the case of a very risk averse fund manager. Note that the likelihood that the manager's portfolio will under-perform, by the time horizon $t=T$, a buy-and-hold benchmark, is in general lower than that for the case in which the benchmark is continuously rebalanced.

\subsubsection{Shadow costs of benchmarking and symmetric liquidity constraints}

Table 7 reports the results for the shadow costs of benchmarking incentives, for the case of a continuously rebalanced benchmark, measured in percent points of the investor's initial wealth, for the case of identical $\left(\sigma_{j}=0.5, \mu_{j}=0.1\right)$, independent, and non-tradeable risky assets $\left(\rho=0, \alpha_{j}=0\right)$. Figure 3 reveals the shape of this shadow cost function, for a particular set of input parameters. Shadow costs range from $0 \%$ to $188.76 \%$ in the unconstrained liquidity case, while ranging from $0 \%$ to $136.21 \%$ for the constrained liquidity one. For $\gamma_{i}=10$, a liquidity constrained investor, with an investment horizon of 2 years, and $\beta_{j}=0.5$, requires $136.21 \%$ extra initial wealth in order to be indifferent between delegating the management of her savings to the professional money manager and directly accessing the financial markets to do it herself. I also investigate whether a constrained professional money manager adjusts her portfolio riskiness through taking on unsystematic rather than systematic risk. Thus, I let 
$\mu_{1}=r=0.02$, so that asset 1 does not command any risk premium, and set $\sigma_{12}=0$, so that asset 1 is solely driven by the source of risk $Z_{1}(t)$. Moreover, let $\beta_{1}=0$ and $\beta_{2}=1$, such that the benchmark portfolio is given by asset 2 alone, and is solely driven by the source of risk $Z_{2}(t)$, so that $\sigma_{21}=0$, which also implies that $\rho=0$. The results obtained under this setup show that, the money manager optimally chooses to hold asset 2 only, in her portfolio, which means that risk-taking happens only through systematic risk. This is the case either when both risky assets are non-tradeable $\left(\alpha_{j}=0\right)$, or when we let asset 2 trade during the year $\left(\alpha_{1}=0\right.$ and $\left.\alpha_{2}=0.20\right)$.

\subsubsection{Implications of benchmarking and asymmetric liquidity constraints}

Consider now the case where we let the maximum number of shares of asset 2 , that can be traded per year, be non-zero. In particular, let $\alpha_{2}=0.20$. Table 8 shows that, not unexpectedly, in this case the optimal initial portfolio risk exposure (the fraction of assets under management invested in risky assets) declines, when compared to the results in Table 5. As the risk aversion parameter of the manager increases, her incentives to herd and to track the exogenous benchmark also increase, and both constrained and unconstrained optimal portfolio allocations tend to get closer to the benchmark portfolio weights. One of the main results of this table is that, compared to the direct investing case, here the illiquidity costs are higher, and increase with $\gamma_{M}$. because the closer the manager wants to track the benchmark, the more she is going to need to have less illiquid assets to do so. Therefore, the costs of not being able to trade and track the benchmark necessarily increase. In other words, it is more costly to the manager to have illiquid assets when she needs more desperately to track a benchmark that includes those assets. The parameter $\mathrm{CV}_{W}$ denotes the cross-sectional variation of the simulated values of the assets under management, which increase with the risk aversion parameter $\gamma_{M}$ because the manager's portfolio is tracking a benchmark that is riskier that the Merton myopic portfolio allocations. Note that now it becomes more likely that the money manager will underperform the benchmark, as given by 
the parameter $\mathrm{P}[W<Y]$. This result seems to relate with the empirical evidence that actively managed funds have, on average, an inferior performance than that of index funds (e.g. Gruber (1996)). These probabilities increase with the risk aversion parameter, and that may be the case because the more risk averse the manager, the higher are her incentives to track the benchmark very closely and, because of illiquidity, the harder to do so.

Compared to Table 5 , here in Table 8 the cross-sectional variations of $\omega_{2}^{c}(T)$ slightly increase, while $\mathrm{CSV}_{W}$ slightly decreases. Furthermore, illiquidity costs significantly increase when we allow asset 2 to trade, even for limited amounts, during the year. Another important result of this table is that denoted by parameter $\mathrm{TE}_{\beta}$, which denotes the tracking error of the manager's portfolio weights, given by $\omega_{j}^{c}(t)$, with respect to the benchmark weights given by $\beta_{j}$. According to these results, the manager's portfolio weights on the less illiquid asset 2 appear to be likely to tilt away from the benchmark weights more than the portfolio weights of more illiquid assets. These tracking errors can be viewed as a measure of risk-shifting by the fund manager. Therefore, we can conclude from these results that the manager's risk-shifting is more likely to happen using less illiquid assets.

I also include in this Table 8 estimates of the parameters $\pi$ and $\nu$, which denote the simulated time-series correlation coefficients of the portfolio liquidity (ratio of $\omega_{2}^{c}(t)$ to $\left.\omega_{1}^{c}(t)\right)$, and the portfolio risk exposure $\left(\omega_{2}^{c}(t)+\omega_{1}^{c}(t)\right)$, respectively, with respect to the ratio of the assets under management to the benchmark portfolio $(\mathrm{W}(\mathrm{t}) / \mathrm{Y}(\mathrm{t}))$. Note that $\pi$ switches from a negative figure to a positive one, as the money manager becomes more conservative. A negative $\pi$ means that, when the performance of the manager's portfolio deteriorates relative to the benchmark, then on average, contemporaneously, the manager optimally chooses to distort her portfolio composition towards the more liquid risky asset, which occurs for the more risk loving managers. These results would be consistent with risk-shifting behavior to take place in the more liquid asset class. Note, however, that these correlations don't appear specially strong. The negative 
signs of $\nu$ all over Table 8 suggest that increasing fund distress implies escalating risk exposure. Shadow costs of benchmarking incentives to a liquidity constrained investor, when asset 2 is tradeable, $\alpha_{j}=0.20$, range from $0 \%$ to $25.87 \%$ of her initial wealth.

\section{Conclusions}

This study was limited in several ways. For ease of exposition, I confine attention to CRRA preferences, continuously rebalanced benchmarks, and totally passive investors. Nevertheless, it suggests that asset illiquidity can significantly affect money managers' risk-shifting incentives as well as the investors' utility costs of misaligned objectives. The main results of this paper also suggest that the value of liquidity is likely to increase with the rise of financial intermediation, and that we should expect the investor's propensity to delegate portfolio decisions to a fund manager to be higher in the presence of illiquid assets and in more illiquid periods.

It would be useful in future research to include a more complicated preference structure in this analysis, and allowing the investor to endogenously decide how much of her savings to hold in the money market account and how much to invest in the managed portfolio, which would allow the investor to trade around incentive misalignments and improve her welfare results. Other interesting extensions could focus on deriving optimal performance benchmarks that would account for asset illiquidity and could then be used to better align incentives between investors and money managers in more illiquid markets. Future work could also focus on studying the implications of timevarying investment opportunities and their interaction with asset illiquidity, as well as on the sensitivity of the results presented here to alternative measures of asset liquidity. Examples of those alternative measures of liquidity include the bid-ask spread (Ami-

hud and Mendelson (1986)), the price impact of trade (Brennan and Subrahmanyam (1996)), turnover (Datar, Naik, and Radcliffe (1998)), trading volume (Brennan, Chordia, and Subrahmanyam (1998)), and transaction costs (Liu and Loewenstein (2002), 
Liu (2004), Dai and Yi (2006), Jang, Koo, Liu, and Loewenstein (2007), and Dai, Jin, and Liu (2008)). Lastly, given that only partial equilibrium results are presented here, they should be taken only as suggestive. Future research could focus on assessing the asset pricing implications of liquidity restrictions in a delegated portfolio general equilibrium setting. Examples of related recent literature on this topic are Longstaff (2005) and Leippold and Rohner (2008). 


\section{Notes}

${ }^{1}$ Chevalier and Ellison (1999) analyze the incentives of mutual fund managers in terms of their career concerns, and find that younger managers are both more likely to be fired for poor performance and (as a result) take on less unsystematic risk than the older managers

${ }^{2}$ See Brunnermeier and Pedersen (2008) for a notable discussion on the mutually reinforcing effects of market liquidity and funding liquidity.

${ }^{3}$ Note that, under liquidity constraints, portfolio weights become random variables, and the manager now needs to care about not only the mean and variance of the risky assets, but also the mean and variance of the portfolio weights, which are out of her control.

${ }^{4}$ Huang, Sialm, and Zhang (2008) show that funds that shift risk end up performing worse, which is consistent with risk-shifting being driven by money managers' opportunistic behavior, rather than their active portfolio management ability.

${ }^{5}$ In a more general model, the investor could be allowed to dynamically choose how much of her portfolio to hold directly in a money market account and how much to hold indirectly on risky assets through the managed portfolios of mutual funds, pension funds, and the like. I am grateful to Joshua Shemesh for this insight.

${ }^{6}$ See Basak and Makarov (2008) for an analysis of the dynamic portfolio choice implications of strategic interaction among money managers.

7 The benchmark portfolio $Y(t)$ could be interpreted as a constraint in the contract decided between the investor and the fund manager at the beginning of the investment period.

${ }^{8}$ In Section 3 , for comparison purposes, I also present results for the simpler case of logarithmic preferences (CRRA utility with $\gamma=1$ ).

9 In a more general model, the investment horizon would not coincide with the fund flows date (e.g. Basak and Makarov (2008)), in which case fund flows would be tradeable after the flow date, and $\phi(t<T)$ would then enter the problem through the budget constraint, and not directly through the utility function.

10 See Brunnermeier (2008) and Allen and Carletti (2008) for excellent accounts of the sequence of events that have mapped out the 2007-08 financial crisis, focusing on a wide range of factors, among which the typical fragility of market liquidity.

${ }^{11}$ It may also be the case that the fund manager has access to the financial markets 
in more favorable terms than the investor. In a more general setting, this situation could be captured by allowing liquidity constraints to be investor-specific and more relaxed to the fund manager. 


\section{References}

Acharya, V. V., and L. H. Pedersen, 2005, "Asset Pricing with Liquidity Risk," Journal of Financial Economics, 77, 375-410.

Allen, F., 2001, "Do Financial Institutions Matter?," Journal of Finance, 56, 11651175.

Allen, F., and E. Carletti, 2008, "The Role of Liquidity in Financial Crises," Working Paper, University of Pennsylvania and University of Frankfurt.

Amihud, Y., and H. Mendelson, 1986, "Asset Pricing and the Bid-Ask Spread," Journal of Financial Economics, 17, 223-249.

Arora, N., and H. Ou-Yang, 2001, "Explicit and Implicit Incentives in a Delegated Portfolio Management Problem: Theory and Evidence," Working Paper, Duke University.

Basak, S., and D. Makarov, 2008, "Strategic Asset Allocation with Relative Performance Concerns," Working Paper, London Business School.

Basak, S., A. Pavlova, and A. Shapiro, 2007, "Optimal Asset Allocation and Risk Shifting in Money Management," Review of Financial Studies, 20, 1583-1621.

, 2008, "Offsetting the Implicit Incentives: Benefits of Benchmarking in Money Management," Journal of Banking and Finance, 32, 1882-1993.

Binsbergen, J. H. V., M. W. Brandt, and R. S. J. Koijen, 2008, "Optimal Decentralized Investment Management," Journal of Finance, 63, 1849-1895.

Brennan, M. J., T. Chordia, and A. Subrahmanyam, 1998, "Alternative Factor Specifications, Security Characteristics, and the Cross-Section of Expected Stock Returns," Journal of Financial Economics, 49, 345-373.

Brennan, M. J., and A. Subrahmanyam, 1996, "Market Microstructure and Asset Pricing: On the Compensation for Illiquidity in Stock Returns," Journal of Financial Economics, 41, 441-464.

Browne, S., 1999, "Beating a Moving Target: Optimal Portfolio Strategies for Outperforming a Stochastic Benchmark," Journal of Finance and Stochastics, 3, 275-294.

Brunnermeier, M. K., 2008, "Deciphering the 2007-08 Liquidity and Credit Crunch," forthcoming, Journal of Economic Perspectives.

Brunnermeier, M. K., and L. H. Pedersen, 2008, "Market Liquidity and Funding Liquidity," forthcoming, Review of Financial Studies. 
Cao, C., T. T. Simin, and Y. Wang, 2007, "Do Mutual Fund Managers Time Market Liquidity?," Working Paper, Pennsylvania State University.

Chevalier, J., and G. Ellison, 1997, "Risk Taking by Mutual Funds as a Response to Incentives," Journal of Political Economy, 105, 1167-1200.

_ 1999, "Career Concerns of Mutual Fund Managers," Quarterly Journal of Economics, 114, 389-432.

Chordia, T., R. Roll, and A. Subrahmanyam, 2000, "Commonality in Liquidity," Journal of Financial Economics, 56, 3-28.

Dai, M., H. Jin, and H. Liu, 2008, "Illiquidity, Portfolio Constraints, and Diversification," Working Paper, National University of Singapore and Washington University in St. Louis.

Dai, M., and F. Yi, 2006, "Finite-Horizon Optimal Investment with Transaction Costs: A Parabolic Double Obstacle Problem," Working Paper, National University of Singapore and South China Normal University.

Datar, V. T., N. Y. Naik, and R. Radcliffe, 1998, "Liquidity and Stock Returns: An Alternative Test," Journal of Financial Markets, 1, 203-219.

Falkenstein, E. G., 1996, "Preferences for Stock Characteristics as Revealed by Mutual Fund Portfolio Holdings," Journal of Finance, 51, 111-135.

Gruber, M. J., 1996, "Another Puzzle: The Growth of Actively Managed Mutual Funds," Journal of Finance, 51, 783-810.

Huang, J., 2008, "Dynamic Liquidity Preferences of Mutual Funds," Working Paper, Boston College.

Huang, J., C. Sialm, and H. Zhang, 2008, "Does Risk Shifting Affect Mutual Fund Performance?," Working Paper, University of Texas at Austin.

Isaenko, S., 2008, "Diversification in Illiquid Market," Working Paper.

Jang, B.-G., H. K. Koo, H. Liu, and M. Loewenstein, 2007, "Liquidity Premia and Transaction Costs," Journal of Finance, 62, 2330-2366.

Leippold, M., and P. Rohner, 2008, "Equilibrium Implications of Delegated Asset Management Under Benchmarking," Working Paper, Imperial College London and University of Zurich.

Liu, H., 2004, "Optimal Consumption and Investment with Transaction Costs and Multiple Risky Assets," Journal of Finance, 59, 289-338. 
Liu, H., and M. Loewenstein, 2002, "Optimal Portfolio Selection with Transaction Costs and Finite Horizons," Review of Financial Studies, 15, 805-835.

Longstaff, F., 2005, "Asset Pricing in Markets with Illiquid Assets," forthcoming, American Economic Review.

Longstaff, F. A., 1995, "How Much Can Marketability Affect Security Values?," Journal of Finance, 50, 1767-1774.

— , 2001, "Optimal Portfolio Choice and the Valuation of Illiquid Securities," Review of Financial Studies, 14, 407-431.

Longstaff, F. A., and E. S. Schwartz, 2001, "Valuing American Options by Simulation: a Simple Least-Squares Approach," Review of Financial Studies, 14, 113-147.

Massa, M., and L. Phalippou, 2005, "Mutual Funds and the Market for Liquidity," Working Paper, INSEAD and University of Amsterdam.

Merton, R. C., 1969, "Lifetime Portfolio Selection Under Uncertainty: The ContinuousTime Case," Review of Economics and Statistics, 51, 307-318.

Sensoy, B. A., 2008, "Performance Evaluation and Self-Designated Benchmark Indexes in the Mutual Fund Industry," forthcoming, Journal of Financial Economics.

Sirri, E. R., and P. Tufano, 1998, "Costly Search and Mutual Fund Flows," Journal of Finance, 53, 1589-1622. 
Table 1: Optimal buy-and-hold $\left(\alpha_{j}=0\right)$ investment policies and illiquidity discounts, with no influence of either explicit or implicit incentives. Illiquidity discount (ID) is defined as the number of basis points the price of the identical risky assets would have to be reduced in order to make the investor/manager indifferent between holding the liquidity-constrained $\left(\omega_{j}^{c}(0)\right)$ and the liquidity-unconstrained $\left(\omega_{j}^{u}(0)\right)$ portfolios. $\mathrm{CSV}_{j}$ denotes the cross-sectional volatility of the simulated constrained portfolio weights, at the terminal date, $\omega_{j}^{c}(T)$, for $j \in\{1,2\}$. Parameters $\sigma_{j}, \rho$, and $\operatorname{RA}\left(\gamma_{i}\right)$, denote the return volatility of the risky assets, the correlation coefficient between the risky assets' returns, and the coefficient of relative risk aversion, respectively.

\begin{tabular}{|c|c|c|c|c|c|c|c|c|c|}
\hline \multicolumn{10}{|c|}{ Panel A: Constrained liquidity, $\alpha_{j}=0, T_{i}=1$} \\
\hline \multirow[b]{2}{*}{$\rho$} & \multirow[b]{2}{*}{$\operatorname{RA}\left(\gamma_{i}\right)$} & \multicolumn{4}{|c|}{$\sigma_{j}=0.3$} & \multicolumn{4}{|c|}{$\sigma_{j}=0.5$} \\
\hline & & $\omega_{j}^{u}(0)$ & $\omega_{j}^{c}(0)$ & $\mathrm{CSV}_{j}$ & $\mathrm{ID}(\mathrm{bp})$ & $\omega_{j}^{u}(0)$ & $\omega_{j}^{c}(0)$ & $\mathrm{CSV}_{j}$ & $\mathrm{ID}(\mathrm{bp})$ \\
\hline \multirow[t]{4}{*}{-0.5} & 1 & 1.778 & 0.500 & 0.1197 & 704.03 & 0.640 & 0.500 & 0.1838 & 83.99 \\
\hline & 2 & 0.889 & 0.500 & 0.1197 & 149.17 & 0.320 & 0.268 & 0.1111 & 44.48 \\
\hline & 5 & 0.356 & 0.328 & 0.0833 & 20.29 & 0.128 & 0.103 & 0.0499 & 19.34 \\
\hline & 10 & 0.178 & 0.165 & 0.0464 & 10.71 & 0.064 & 0.050 & 0.0261 & 9.99 \\
\hline \multirow[t]{4}{*}{0} & 1 & 0.889 & 0.500 & 0.0996 & 136.55 & 0.320 & 0.305 & 0.1075 & 12.82 \\
\hline & 2 & 0.444 & 0.440 & 0.0891 & 5.73 & 0.160 & 0.153 & 0.0649 & 8.93 \\
\hline & 5 & 0.178 & 0.175 & 0.0444 & 3.54 & 0.064 & 0.060 & 0.0298 & 4.39 \\
\hline & 10 & 0.089 & 0.085 & 0.0243 & 2.15 & 0.032 & 0.030 & 0.0158 & 2.40 \\
\hline \multirow[t]{4}{*}{0.5} & 1 & 0.593 & 0.500 & 0.0718 & 11.70 & 0.213 & 0.210 & 0.0713 & 5.76 \\
\hline & 2 & 0.296 & 0.293 & 0.0527 & 1.61 & 0.107 & 0.100 & 0.0430 & 4.92 \\
\hline & 5 & 0.119 & 0.115 & 0.0291 & 1.92 & 0.043 & 0.040 & 0.0199 & 2.61 \\
\hline & 10 & 0.059 & 0.058 & 0.0164 & 1.23 & 0.021 & 0.020 & 0.0105 & 1.41 \\
\hline
\end{tabular}

Panel B: Constrained liquidity, $\alpha_{j}=0, T_{i}=2$

\begin{tabular}{|c|c|c|c|c|c|c|c|c|c|}
\hline \multirow[b]{2}{*}{$\rho$} & \multirow[b]{2}{*}{$\operatorname{RA}\left(\gamma_{i}\right)$} & \multicolumn{4}{|c|}{$\sigma_{j}=0.3$} & \multicolumn{4}{|c|}{$\sigma_{j}=0.5$} \\
\hline & & $\omega_{j}^{u}(0)$ & $\omega_{j}^{c}(0)$ & $\mathrm{CSV}_{j}$ & $\mathrm{ID}(\mathrm{bp})$ & $\omega_{j}^{u}(0)$ & $\omega_{j}^{c}(0)$ & $\mathrm{CSV}_{j}$ & $\mathrm{ID}(\mathrm{bp})$ \\
\hline \multirow[t]{4}{*}{-0.5} & 1 & 1.778 & 0.500 & 0.1620 & $1,380.80$ & 0.640 & 0.473 & 0.2258 & 285.84 \\
\hline & 2 & 0.889 & 0.500 & 0.1620 & 336.82 & 0.320 & 0.230 & 0.1351 & 158.06 \\
\hline & 5 & 0.356 & 0.313 & 0.1124 & 76.34 & 0.128 & 0.088 & 0.0645 & 68.84 \\
\hline & 10 & 0.178 & 0.155 & 0.0645 & 40.49 & 0.064 & 0.043 & 0.0347 & 35.52 \\
\hline \multirow[t]{4}{*}{0} & 1 & 0.889 & 0.500 & 0.1364 & 286.80 & 0.320 & 0.293 & 0.1419 & 63.84 \\
\hline & 2 & 0.444 & 0.430 & 0.1209 & 29.70 & 0.160 & 0.140 & 0.0873 & 41.65 \\
\hline & 5 & 0.178 & 0.170 & 0.0634 & 16.78 & 0.064 & 0.053 & 0.0405 & 19.67 \\
\hline & 10 & 0.089 & 0.083 & 0.0356 & 9.80 & 0.032 & 0.025 & 0.0210 & 10.43 \\
\hline \multirow[t]{4}{*}{0.5} & 1 & 0.593 & 0.500 & 0.0999 & 29.83 & 0.213 & 0.205 & 0.0984 & 28.23 \\
\hline & 2 & 0.296 & 0.298 & 0.0754 & 9.41 & 0.107 & 0.095 & 0.0605 & 21.92 \\
\hline & 5 & 0.119 & 0.115 & 0.0431 & 8.38 & 0.043 & 0.038 & 0.0292 & 10.96 \\
\hline & 10 & 0.059 & 0.058 & 0.0250 & 5.24 & 0.021 & 0.018 & 0.0149 & 5.86 \\
\hline
\end{tabular}


Table 2: Optimal investment policies and costs of constant illiquidity, with no influence of implicit incentives $(Y(t)=1)$, when asset 1 is non-tradeable $\left(\alpha_{1}=0\right)$, and asset 2 has limited trading per year $\left(\alpha_{2}=0.1\right), \sigma_{j}=0.5$, and $T_{i}=1$. Illiquidity cost (IC) is defined as the amount of initial wealth (in basis points) that we would have to give the investor/manager in order to make her indifferent between holding the liquidity constrained and the liquidity unconstrained portfolios. $\mathrm{CSV}_{W}$ denotes the cross-sectional volatility of the simulated value of assets under management, under liquidity constraints, at the terminal date, $\mathrm{W}(\mathrm{T})$. The variable $\mathrm{E}\left[\omega_{j}^{c}(T)\right]$ denotes the expected value of the constrained portfolio weight for asset $j$, at the terminal date.

\begin{tabular}{|c|c|c|c|c|c|c|c|c|}
\hline$\rho$ & $\operatorname{RA}\left(\gamma_{i}\right)$ & $\mathrm{IC}(\mathrm{bp})$ & $\mathrm{CSV}_{W}$ & Asset $j$ & $\omega_{j}^{u}(0)$ & $\omega_{j}^{c}(0)$ & $\mathrm{E}\left[\omega_{j}^{c}(T)\right]$ & $\mathrm{CSV}_{j}$ \\
\hline \multirow{8}{*}{-0.5} & 1 & 84.70 & 0.3195 & 1 & 0.640 & 0.500 & 0.500 & 0.1838 \\
\hline & & & & 2 & 0.640 & 0.500 & 0.500 & 0.1838 \\
\hline & 2 & 52.27 & 0.1660 & 1 & 0.320 & 0.276 & 0.279 & 0.1100 \\
\hline & & & & 2 & 0.320 & 0.184 & 0.287 & 0.1230 \\
\hline & 5 & 28.61 & 0.0671 & 1 & 0.128 & 0.105 & 0.110 & 0.0505 \\
\hline & & & & 2 & 0.128 & 0.045 & 0.147 & 0.0693 \\
\hline & 10 & 23.63 & 0.0389 & 1 & 0.064 & 0.054 & 0.057 & 0.0278 \\
\hline & & & & 2 & 0.064 & 0.006 & 0.106 & 0.0493 \\
\hline \multirow{6}{*}{0} & 1 & 16.18 & 0.2583 & 1 & 0.320 & 0.285 & 0.284 & 0.1039 \\
\hline & & & & 2 & 0.320 & 0.285 & 0.376 & 0.1271 \\
\hline & 2 & 12.45 & 0.1266 & 1 & 0.160 & 0.150 & 0.154 & 0.0641 \\
\hline & & & & 2 & 0.160 & 0.100 & 0.200 & 0.0837 \\
\hline & 5 & 11.58 & 0.0508 & 1 & 0.064 & 0.059 & 0.062 & 0.0291 \\
\hline & & & & 2 & 0.064 & 0.007 & 0.107 & 0.0501 \\
\hline \multirow{10}{*}{0.5} & 10 & 17.70 & 0.0368 & 1 & 0.032 & 0.030 & 0.032 & 0.0157 \\
\hline & & & & 2 & 0.032 & 0 & 0.097 & 0.0435 \\
\hline & 1 & 7.82 & 0.2132 & 1 & 0.213 & 0.222 & 0.222 & 0.0745 \\
\hline & & & & 2 & 0.213 & 0.148 & 0.244 & 0.0842 \\
\hline & 2 & 8.30 & 0.1027 & 1 & 0.107 & 0.105 & 0.108 & 0.0450 \\
\hline & & & & 2 & 0.107 & 0.045 & 0.145 & 0.0606 \\
\hline & 5 & 9.49 & 0.0479 & 1 & 0.043 & 0.040 & 0.042 & 0.0199 \\
\hline & & & & 2 & 0.043 & 0 & 0.097 & 0.0440 \\
\hline & 10 & 19.88 & 0.0352 & 1 & 0.021 & 0.010 & 0.011 & 0.0053 \\
\hline & & & & 2 & 0.021 & 0 & 0.098 & 0.0430 \\
\hline
\end{tabular}


Table 3: Shadow costs of explicit incentives derived from differences in risk appetites between the investor and the money manager, where $T_{i}=1$. Shadow cost is defined as the additional percentage of the investor's initial wealth that we would have to give her in order to make her indifferent between delegating the administration of her savings to a money manager, and administering those savings herself. Using standard working practice, these utility losses are computed via taking the ratio of the annualized certainty equivalent rates of return, achieved under the investor's portfolio delegated and centralized problems, after which I subtract one and multiply by 100 to express the losses in percent points per year. Parameter values are as in Table1.

\begin{tabular}{|c|c|c|c|c|c|c|c|c|c|}
\hline \multicolumn{10}{|c|}{ Panel A: Unconstrained liquidity, $T_{i}=1$} \\
\hline & \multirow[b]{2}{*}{$\rho$} & \multicolumn{2}{|c|}{$\gamma_{I}=1$} & \multicolumn{2}{|c|}{$\gamma_{I}=2$} & \multicolumn{2}{|c|}{$\gamma_{I}=5$} & \multicolumn{2}{|c|}{$\gamma_{I}=10$} \\
\hline & & $\sigma_{j}=0.3$ & 0.5 & 0.3 & 0.5 & 0.3 & 0.5 & 0.3 & 0.5 \\
\hline \multirow{3}{*}{$\gamma_{M}=1$} & -0.5 & 0 & 0 & 7.78 & 2.72 & 64.60 & 18.40 & 250.33 & 55.13 \\
\hline & 0 & 0 & 0 & 3.67 & 1.30 & 26.20 & 8.54 & 82.92 & 22.96 \\
\hline & 0.5 & 0 & 0 & 2.41 & 0.86 & 16.47 & 5.57 & 46.52 & 14.54 \\
\hline \multirow{3}{*}{$\gamma_{M}=2$} & -0.5 & 3.51 & 1.22 & 0 & 0 & 6.79 & 2.41 & 27.12 & 8.71 \\
\hline & 0 & 1.77 & 0.63 & 0 & 0 & 3.26 & 1.17 & 12.12 & 4.17 \\
\hline & 0.5 & 1.19 & 0.42 & 0 & 0 & 2.15 & 0.77 & 7.83 & 2.74 \\
\hline \multirow{3}{*}{$\gamma_{M}=5$} & -0.5 & 9.38 & 3.24 & 2.55 & 0.89 & 0 & 0 & 1.46 & 0.54 \\
\hline & 0 & 4.63 & 1.63 & 1.28 & 0.45 & 0 & 0 & 0.72 & 0.26 \\
\hline & 0.5 & 3.07 & 1.09 & 0.86 & 0.31 & 0 & 0 & 0.47 & 0.17 \\
\hline \multirow{3}{*}{$\gamma_{M}=10$} & -0.5 & 12.05 & 4.14 & 4.61 & 1.61 & 0.70 & 0.24 & 0 & 0 \\
\hline & 0 & 5.90 & 2.08 & 2.29 & 0.81 & 0.35 & 0.12 & 0 & 0 \\
\hline & 0.5 & 3.91 & 1.39 & 1.53 & 0.54 & 0.24 & 0.08 & 0 & 0 \\
\hline
\end{tabular}

\begin{tabular}{|c|c|c|c|c|c|c|c|c|c|}
\hline \multicolumn{10}{|c|}{ Panel B: Constrained liquidity, $\alpha_{j}=0, T_{i}=1$} \\
\hline & \multirow[b]{2}{*}{$\rho$} & \multicolumn{2}{|c|}{$\gamma_{I}=1$} & \multicolumn{2}{|c|}{$\gamma_{I}=2$} & \multicolumn{2}{|c|}{$\gamma_{I}=5$} & \multicolumn{2}{|c|}{$\gamma_{I}=10$} \\
\hline & & $\sigma_{j}=0.3$ & 0.5 & 0.3 & 0.5 & 0.3 & 0.5 & 0.3 & 0.5 \\
\hline \multirow{3}{*}{$\gamma_{M}=1$} & -0.5 & 0 & 0 & 0 & 1.62 & 0.69 & 11.70 & 5.50 & 32.66 \\
\hline & 0 & 0 & 0 & 0.07 & 1.17 & 4.96 & 7.06 & 16.95 & 16.28 \\
\hline & 0.5 & 0 & 0 & 1.13 & 0.81 & 10.37 & 4.62 & 29.93 & 10.12 \\
\hline \multirow{3}{*}{$\gamma_{M}=2$} & -0.5 & 0 & 1.00 & 0 & 0 & 0.69 & 1.80 & 5.50 & 5.82 \\
\hline & 0 & 0.44 & 0.59 & 0 & 0 & 3.19 & 1.03 & 11.46 & 3.24 \\
\hline & 0.5 & 1.09 & 0.43 & 0 & 0 & 1.93 & 0.61 & 6.59 & 1.97 \\
\hline \multirow{3}{*}{$\gamma_{M}=5$} & -0.5 & 2.04 & 2.71 & 1.35 & 0.74 & 0 & 0 & 1.21 & 0.35 \\
\hline & 0 & 3.20 & 1.54 & 1.24 & 0.41 & 0 & 0 & 0.66 & 0.23 \\
\hline & 0.5 & 2.97 & 1.06 & 0.86 & 0.28 & 0 & 0 & 0.40 & 0.15 \\
\hline \multirow{3}{*}{$\gamma_{M}=10$} & -0.5 & 4.31 & 3.46 & 3.19 & 1.34 & 0.04 & 0.20 & 0 & 0 \\
\hline & 0 & 4.48 & 1.96 & 2.26 & 0.74 & 0.35 & 0.10 & 0 & 0 \\
\hline & 0.5 & 3.79 & 1.34 & 1.51 & 0.51 & 0.23 & 0.07 & 0 & 0 \\
\hline
\end{tabular}


Table 4: Optimal investment policies and costs of time-varying illiquidity, with no influence of implicit incentives $(Y(t)=1)$, for independent risky assets $(\rho=0)$, where asset 1 is nontradeable $\left(\alpha_{1}(t)=0\right)$, and asset 2 has limited time-varying trading per year, for a liquidity volatility parameter value of $\sigma_{\alpha_{2}}=0.2$, speed of reversion $K_{2}=0.1$, initial level $\psi_{2}(0)=0.1$ (annualized), long-run equilibrium level $\theta_{2}=0.1$ (annualized), $\sigma_{j}=0.5$, and $T_{i}=1$. The parameter $\lambda_{j 2}$ denotes the simulated average time-series correlation between $\omega_{j}^{c}(t)$ and the stochastic liquidity boundary $\psi_{2}(t)$, for $j \in\{1,2\}$.

\begin{tabular}{ccccccccc}
\hline \multicolumn{7}{c}{ Panel A: Stochastic constrained liquidity, $\theta_{2}=0.1$} \\
\hline $\mathrm{RA}\left(\gamma_{i}\right)$ & $\mathrm{IC}(\mathrm{bp})$ & $\mathrm{CSV}_{W}$ & Asset $j$ & $\omega_{j}^{u}(0)$ & $\omega_{j}^{c}(0)$ & $\lambda_{j 2}$ & $\mathrm{E}\left[\omega_{j}^{c}(T)\right]$ & $\mathrm{CSV}_{j}$ \\
\hline 1 & 17.00 & 0.2580 & 1 & 0.320 & 0.280 & -0.3646 & 0.282 & 0.1033 \\
& & & 2 & 0.320 & 0.280 & 0.8221 & 0.377 & 0.1340 \\
2 & \multirow{2}{*}{13.59} & \multirow{2}{*}{0.1283} & 1 & 0.160 & 0.150 & -0.1551 & 0.154 & 0.0641 \\
& & & 2 & 0.160 & 0.100 & 0.6649 & 0.205 & 0.0930 \\
5 & \multirow{2}{*}{13.46} & \multirow{2}{*}{0.0508} & 1 & 0.064 & 0.054 & -0.0556 & 0.057 & 0.0271 \\
& & & 2 & 0.064 & 0.006 & 0.2548 & 0.111 & 0.0603 \\
10 & \multirow{2}{*}{20.65} & \multirow{2}{*}{0.0386} & 1 & 0.032 & 0.030 & -0.0476 & 0.032 & 0.0157 \\
& & & 2 & 0.032 & 0 & 0.2276 & 0.102 & 0.0525 \\
\hline \hline
\end{tabular}

Panel B: Stochastic constrained liquidity, $\theta_{2}=0.2$

\begin{tabular}{ccccccccc}
\hline $\mathrm{RA}\left(\gamma_{i}\right)$ & $\mathrm{IC}(\mathrm{bp})$ & $\mathrm{CSV}_{W}$ & $\mathrm{Asset} j$ & $\omega_{j}^{u}(0)$ & $\omega_{j}^{c}(0)$ & $\lambda_{j 2}$ & $\mathrm{E}\left[\omega_{j}^{c}(T)\right]$ & $\mathrm{CSV}_{j}$ \\
\hline 1 & 17.18 & 0.2586 & 1 & 0.320 & 0.280 & -0.3452 & 0.282 & 0.1034 \\
& & & 2 & 0.320 & 0.280 & 0.9035 & 0.380 & 0.1352 \\
\cline { 4 - 8 } 2 & \multirow{2}{*}{13.89} & 0.1289 & 1 & 0.160 & 0.150 & -0.1554 & 0.154 & 0.0641 \\
& & & 2 & 0.160 & 0.100 & 0.8528 & 0.208 & 0.0946 \\
5 & \multirow{2}{*}{13.99} & \multirow{2}{*}{0.0516} & 1 & 0.064 & 0.054 & -0.0645 & 0.057 & 0.0271 \\
& & & 2 & 0.064 & 0.006 & 0.5012 & 0.115 & 0.0622 \\
10 & 22.06 & \multirow{2}{*}{0.0394} & 1 & 0.032 & 0.030 & -0.0572 & 0.032 & 0.0157 \\
& & & 2 & 0.032 & 0 & 0.4760 & 0.105 & 0.0543 \\
\hline
\end{tabular}


Table 5: Optimal investment policies and illiquidity discounts, under the influence of benchmarking incentives $(\phi(T)=1 / Y(T))$, for a continuously rebalancing benchmark with $\beta_{j}=0.5$, and independent $(\rho=0)$ non-tradeable $\left(\alpha_{j}=0\right)$ risky assets. Illiquidity discounts are defined as the number of basis points the price of the identical risky assets would have to be reduced in order to make the manager indifferent between holding the liquidity constrained and the liquidity unconstrained portfolios. $\mathrm{CSV}_{j}$ denotes the cross-sectional volatility of the simulated constrained portfolio weights, at the terminal date, $\omega_{j}^{c}(T)$, for $j \in\{1,2\}$.

\begin{tabular}{ccccccccc}
\hline \multicolumn{6}{c}{ Panel A: Rebalancing Benchmark with $\beta_{j}=0.5, \alpha_{j}=0, T_{M}=1, \rho=0$} & $\left(\mathrm{CSV}_{Y}=0.404\right)$ \\
\hline $\mathrm{RA}\left(\gamma_{M}\right)$ & $\omega_{j}^{u}(0)$ & $\omega_{j}^{c}(0)$ & $\mathrm{CSV}_{j}$ & $\mathrm{TE}_{\beta}$ & $\mathrm{ID}(\mathrm{bp})$ & $\mathrm{CSV}_{W}$ & $\mathrm{TE}_{Y}$ & $\mathrm{P}[\mathrm{W}<\mathrm{Y}]$ \\
\hline 1 & 0.320 & 0.305 & 0.1075 & 19.71 & 12.82 & 0.2543 & 3.09 & 0.5173 \\
2 & 0.410 & 0.395 & 0.1289 & 12.60 & 39.27 & 0.3294 & 2.03 & 0.5344 \\
5 & 0.464 & 0.450 & 0.1424 & 10.07 & 108.95 & 0.3752 & 1.56 & 0.5864 \\
\hline \hline \multicolumn{7}{c}{ Panel B: Rebalancing Benchmark with $\beta_{j}=0.5, \alpha_{j}=0, T_{M}=2, \rho=0\left(\mathrm{CSV}_{Y}=0.655\right)$} \\
\hline $\mathrm{RA}\left(\gamma_{M}\right)$ & $\omega_{j}^{u}(0)$ & $\omega_{j}^{c}(0)$ & $\mathrm{CSV}_{j}$ & $\mathrm{TE}_{\beta}$ & $\mathrm{ID}(\mathrm{bp})$ & $\mathrm{CSV}_{W}$ & $\mathrm{TE}_{Y}$ & $\mathrm{P}[\mathrm{W}<\mathrm{Y}]$ \\
\hline 1 & 0.320 & 0.290 & 0.1412 & 22.01 & 63.84 & 0.4049 & 3.55 & 0.5264 \\
2 & 0.410 & 0.385 & 0.1685 & 15.42 & 156.63 & 0.5375 & 2.54 & 0.5503 \\
5 & 0.464 & 0.445 & 0.1862 & 13.40 & 360.01 & 0.6213 & 2.12 & 0.6099 \\
\hline
\end{tabular}


Table 6: Optimal investment policies and illiquidity discounts, under the influence of benchmarking incentives, where $\phi(T)=1 / Y(T)$, for a buy-and-hold benchmark with $\beta_{j}=0.5$, and independent $(\rho=0)$ non-tradeable $\left(\alpha_{j}=0\right)$ risky assets. Tracking errors $(\mathrm{TE})$ are measured as the square root of the non-central second moment of the deviations between the money manager's portfolio weights/returns and the benchmark weights/returns. The simulated probabilities that the money manager's optimal portfolio values end up below those of the benchmark, by the terminal date, are represented by $\mathrm{P}[\mathrm{W}<\mathrm{Y}]$.

\begin{tabular}{cccccccccc}
\hline \multicolumn{6}{c}{ Buy-and-Hold Benchmark with $\beta_{i}=0.5, \alpha_{i}=0, T_{M}=1, \rho=0\left(\mathrm{CSV}_{Y}=0.4169\right)$} \\
\hline $\mathrm{RA}\left(\gamma_{M}\right)$ & $\omega_{i}^{u}(0)$ & $\omega_{i}^{c}(0)$ & $\mathrm{CSV}_{u}$ & $\mathrm{CSV}_{c}$ & $\mathrm{TE}_{\beta}$ & $\mathrm{ID}(\mathrm{bp})$ & $\mathrm{CSV}_{W}$ & $\mathrm{TE}_{Y}$ & $\mathrm{P}[\mathrm{W}<\mathrm{Y}]$ \\
\hline 1 & 0.320 & 0.305 & 0.1021 & 0.1075 & 19.27 & 2.24 & 0.2543 & 2.97 & 0.5147 \\
2 & 0.410 & 0.405 & 0.1309 & 0.1313 & 9.50 & 2.05 & 0.3377 & 1.46 & 0.5147 \\
5 & 0.464 & 0.465 & 0.1481 & 0.1464 & 3.54 & 1.13 & 0.3878 & 0.55 & 0.5146 \\
10 & 0.482 & 0.480 & 0.1538 & 0.1505 & 2.03 & 0.63 & 0.4003 & 0.31 & 0.5146 \\
\hline
\end{tabular}


Table 7: Shadow costs of benchmarking incentives $(\phi(T)=1 / Y(T))$, when the benchmark is continuously rebalanced, the risky assets are independent $(\rho=0)$ and non-tradeable $\left(\alpha_{j}=0\right)$. These shadows costs are measured in percentage points, for different investment horizons $T_{i}$, and different benchmark portfolio weights $\beta_{j}$.

\begin{tabular}{|c|c|c|c|c|}
\hline \multicolumn{5}{|c|}{ Panel A: Unconstrained liquidity } \\
\hline \multirow[b]{2}{*}{$\operatorname{RA}\left(\gamma_{i}\right)$} & \multicolumn{2}{|c|}{$\beta_{j}=0.2$} & \multicolumn{2}{|c|}{$\beta_{j}=0.5$} \\
\hline & $T_{i}=1$ & 2 & 1 & 2 \\
\hline 1 & 0 & 0 & 0 & 0 \\
\hline 2 & 0.51 & 1.02 & 3.20 & 6.50 \\
\hline 5 & 3.26 & 6.64 & 22.25 & 50.31 \\
\hline 10 & 8.39 & 17.78 & 67.11 & 188.76 \\
\hline \multicolumn{5}{|c|}{ Panel B: Constrained liquidity, $\alpha_{j}=0$} \\
\hline & \multicolumn{2}{|c|}{$\beta_{j}=0.2$} & \multicolumn{2}{|c|}{$\beta_{j}=0.5$} \\
\hline $\operatorname{RA}\left(\gamma_{i}\right)$ & $T_{i}=1$ & 2 & 1 & 2 \\
\hline 1 & 0 & 0 & 0 & 0 \\
\hline 2 & 0.44 & 0.85 & 3.00 & 5.82 \\
\hline 5 & 2.81 & 4.82 & 20.32 & 41.28 \\
\hline 10 & 6.44 & 10.71 & 58.25 & 136.21 \\
\hline
\end{tabular}


Table 8: Optimal investment policies and costs of constant illiquidity, under the influence of benchmarking incentives $(\phi(T)=1 / Y(T))$, for a continuously rebalanced benchmark with $\beta_{j}=0.5$, when asset 1 is non-tradeable $\left(\alpha_{1}=0\right)$, and asset 2 has limited trading per year $\left(\alpha_{2}=0.2\right), \sigma_{j}=0.5$, and $T_{i}=1$. Illiquidity cost (IC) is defined as the additional amount of initial wealth (in basis points) that we would have to give the fund manager in order to make her indifferent between holding the liquidity constrained and the liquidity unconstrained portfolios. $\mathrm{CSV}_{Y}$ denotes the cross-sectional volatility of the simulated value of the rebalanced benchmark. These panels consider the case of independent risky assets $(\rho=0)$, which results in $\mathrm{CSV}_{Y}=0.4040$. Each panel also includes values for the parameters $\pi$ and $\nu$, which denote the simulated time-series correlation coefficients of the portfolio liquidity (ratio of $\omega_{2}^{c}(t)$ to $\omega_{1}^{c}(t)$ ), and the portfolio risk exposure $\left(\omega_{2}^{c}(t)+\omega_{1}^{c}(t)\right)$, respectively, with the ratio of the assets under management to the benchmark portfolio $(\mathrm{W}(\mathrm{t}) / \mathrm{Y}(\mathrm{t}))$.

\begin{tabular}{|c|c|c|c|c|c|c|c|c|c|c|}
\hline$\gamma_{M}$ & $\mathrm{IC}(\mathrm{bp})$ & $\mathrm{CSV}_{W}$ & $\mathrm{TE}_{Y}$ & $\mathrm{P}[\mathrm{W}<\mathrm{Y}]$ & $j$ & $\omega_{j}^{u}(0)$ & $\omega_{j}^{c}(0)$ & $\mathrm{E}\left[\omega_{j}^{c}(T)\right]$ & $\mathrm{CSV}_{j}$ & $\mathrm{TE}_{\beta}$ \\
\hline \multirow[t]{2}{*}{1} & 19.32 & 0.2572 & 3.22 & 0.5215 & 1 & 0.320 & 0.306 & 0.306 & 0.1073 & 19.63 \\
\hline & & & & & 2 & 0.320 & 0.204 & 0.395 & 0.1409 & 21.57 \\
\hline \multirow[t]{2}{*}{2} & 54.18 & 0.3318 & 2.21 & 0.5367 & 1 & 0.410 & 0.414 & 0.411 & 0.1293 & 11.29 \\
\hline & & & & & 2 & 0.410 & 0.276 & 0.465 & 0.1575 & 16.39 \\
\hline \multirow[t]{5}{*}{5} & 138.21 & 0.4061 & 1.51 & 0.6476 & 1 & 0.464 & 0.455 & 0.457 & 0.1514 & 10.28 \\
\hline & & & & & 2 & 0.464 & 0.455 & 0.539 & 0.1529 & 10.28 \\
\hline & & & & & & & $\gamma_{M}=1$ & 2 & 5 & 10 \\
\hline & & & & & & $\pi$ & -0.0660 & -0.1923 & 0.1626 & 0.1376 \\
\hline & & & & & & $\nu$ & -0.3804 & -0.2620 & -0.2571 & -0.2507 \\
\hline
\end{tabular}




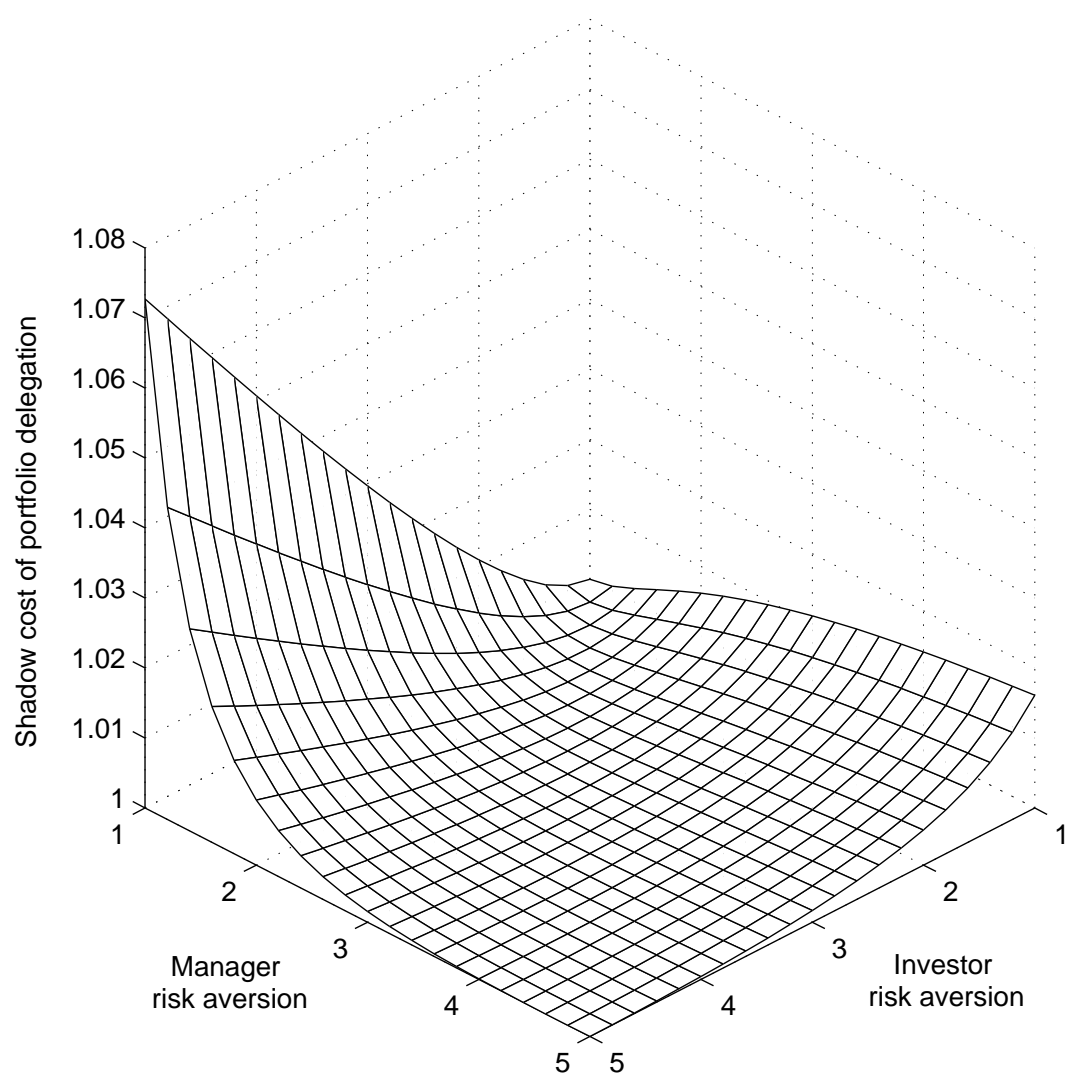

Figure 1: Shadow cost derived from explicit incentives only, due to differences in risk appetites between the investor and the fund manager. These costs are measured as factors we would have to multiply the investor's initial wealth with, in order to compensate her for the effect of suboptimal policies derived from portfolio delegation. This is also the case of identical, independent, and non-tradeable $\left(\alpha_{j}=0\right)$ risky assets, where $r=0.02, \mu_{j}=0.10$, and $\sigma_{j}=0.5$, for $j \in\{1,2\}$, and $T_{i}=1$. 


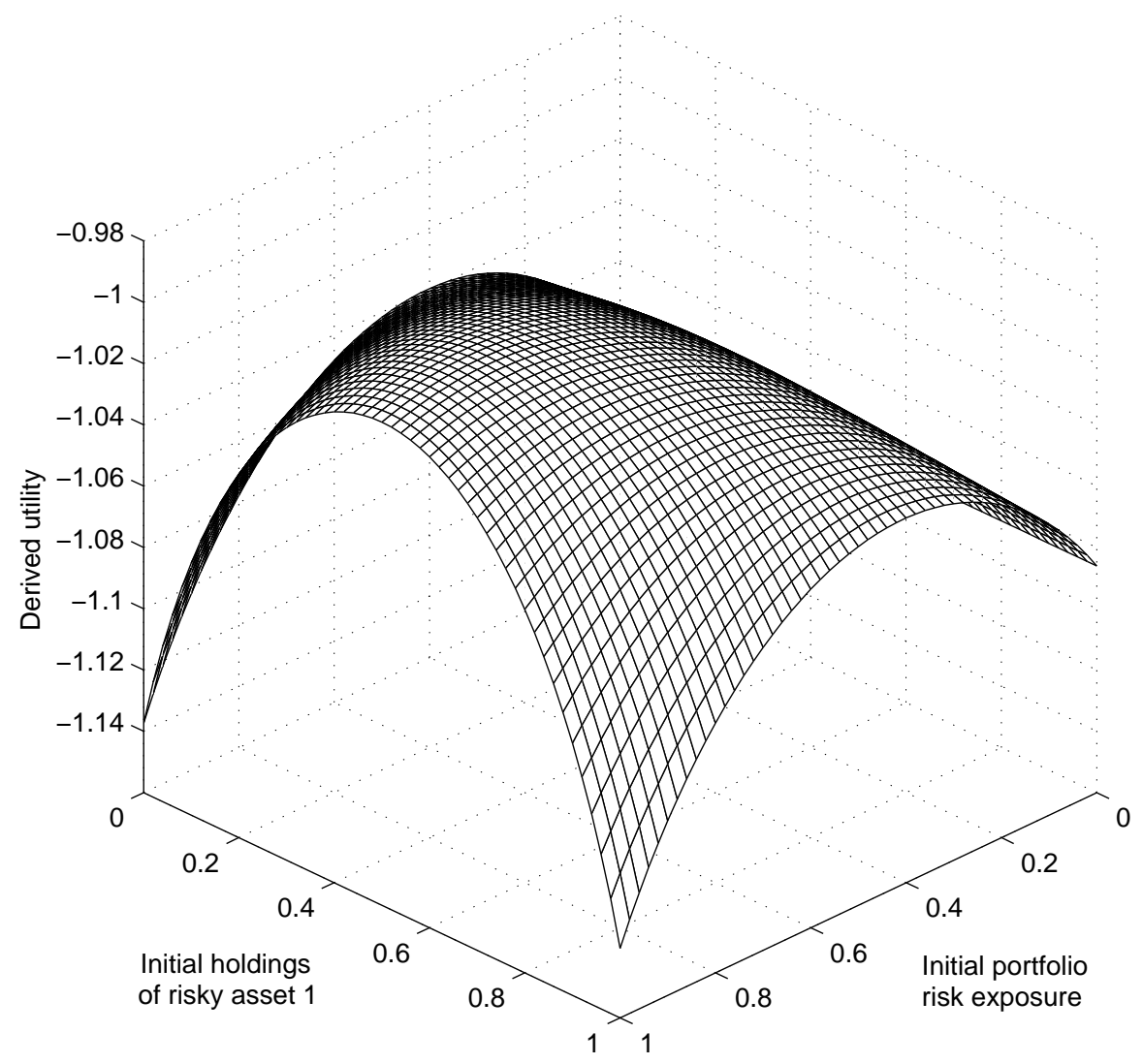

Figure 2: Derived utility of terminal wealth function, for a CRRA manager, with $\gamma_{M}=2$, whose performance is measured relative to a benchmark, with $\beta_{j}=0.5$, and where the flow-to-performance specification is given by: $\phi(T)=1 / Y(T)$. This manager chooses, at time $t=0$, to hold $\omega_{1}(0)$ and $\omega_{2}(0)$, on risky assets 1 and 2, respectively, and these initial allocations cannot be revised for $t>0\left(\alpha_{j}=0\right)$. The values on the axis for initial holdings of risky asset 1 are fractions of the initial total portfolio risky exposure $\left(\omega_{1}(0)+\omega_{2}(0)\right)$. These are identical and independent risky assets, where $r=0.02, \mu_{j}=0.10$, and $\sigma_{j}=0.5$, for $j \in\{1,2\}$. 


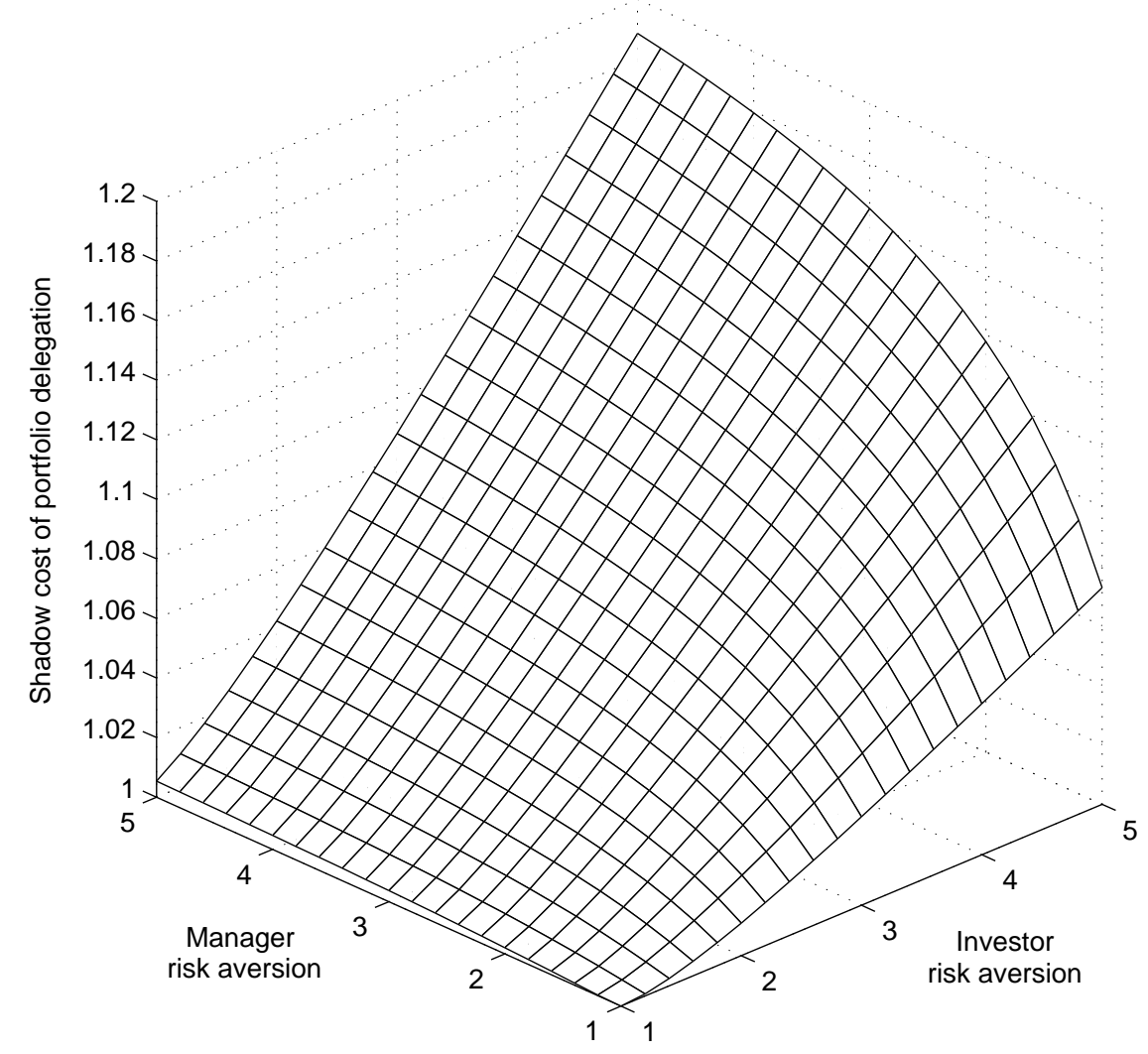

Figure 3: Shadow cost (vertical axis) derived from explicit and benchmarking (implicit) incentives, together, due to portfolio delegation, as a function of the risk aversion parameters for the investor and the fund manager (horizontal axes). This is the case of a manager whose performance is measured relative to a benchmark $Y(t)$, with $\beta_{j}=0.5$, and where the fund flow-to-performance specification is given by: $\phi(T)=1 / Y(T)$. These costs are measured as factors we would have to multiply the investor's initial wealth with, in order to compensate her for the effect of suboptimal policies derived from portfolio delegation. This is also the case of identical, independent, and nontradeable $\left(\alpha_{j}=0\right)$ risky assets, where $r=0.02, \mu_{j}=0.10$, and $\sigma_{j}=0.5$, for $j \in\{1,2\}$, and $T_{i}=1$. 